This item was submitted to Loughborough's Research Repository by the author.

Items in Figshare are protected by copyright, with all rights reserved, unless otherwise indicated.

\title{
Ice vs. steel: Ballistic impact of woven carbon/epoxy composites. Part I - Deformation and damage behaviour
}

PLEASE CITE THE PUBLISHED VERSION

https://doi.org/10.1016/j.engfracmech.2018.12.003

PUBLISHER

(C) Elsevier

VERSION

AM (Accepted Manuscript)

\section{PUBLISHER STATEMENT}

This paper was accepted for publication in the journal Engineering Fracture Mechanics and the definitive published version is available at https://doi.org/10.1016/j.engfracmech.2018.12.003

LICENCE

CC BY-NC-ND 4.0

\section{REPOSITORY RECORD}

Coles, Laurence A., Anish Roy, Nickolay Sazhenkov, Leonid Voronov, Mikhail Nikhamkin, and Vadim Silberschmidt. 2018. "Ice Vs. Steel: Ballistic Impact of Woven Carbon/epoxy Composites. Part I - Deformation and Damage Behaviour”. figshare. https://hdl.handle.net/2134/36531. 


\title{
Ice $v s$. steel: Ballistic impact of woven carbon/epoxy composites. Part I - Deformation and damage behaviour
}

\author{
Laurence A. Coles ${ }^{\mathrm{a}}$, Anish Roy ${ }^{\mathrm{a}}$, Nickolay Sazhenkov ${ }^{\mathrm{b}}$, Leonid Voronov ${ }^{\mathrm{b}}$, \\ Mikhail Nikhamkin ${ }^{\mathrm{b}}$, Vadim V. Silberschmidt ${ }^{\mathrm{a}}$, \\ ${ }^{a}$ Wolfson School of Mechanical, Electrical and Manufacturing Engineering, Loughborough University, Leicestershire LE11 $3 T U$, UK \\ ${ }^{\mathrm{b}}$ Aircraft Engines Department, Perm National Research Polytechnical University, Komsomolsky prosp., 29, 614000 Perm, Russian Federation
}

A B S T R A C T

\begin{abstract}
With extensive use of composite materials in aerospace, marine, energy and defence applications, their susceptibility to impact events is still an unresolved problem. In this paper, impacts of carbon fibre/epoxy composite specimens with solid (steel) and fragmenting (ice) spherical projectiles are studied extensively, using a combination of non-invasive analysis techniques to assess their dynamic deformation behaviour and resultant damage. The velocity magnitudes of highintensity impacts varied between 70 and $90 \mathrm{~m} / \mathrm{s}$ for solid projectiles and between 300 and $500 \mathrm{~m} / \mathrm{s}$ for fragmenting ones, resulting in three consistent and comparable levels of structural damage for both cases. A new in-depth deformation analysis method based on high-speed digital image correlation was utilised to assess the effect of both the projectile type and impact velocity, resulting in a deeper understanding of the specimen's deformation behaviour allowing detailed observation of its stages during the impact event. Additionally, both visual and non-invasive methods were employed to analyse the extent of damage related to various dynamic loading conditions. X-ray computed tomography was used to implement a full volumetric analysis of internal damage and resulted in a detailed insight into inter- and intra-ply damage modes.
\end{abstract}

\author{
Keywords: \\ Fibre-reinforced composites \\ Blast \\ Failure assessment \\ Delamination \\ X-ray tomography
}

\section{Introduction}

Over the last decades, the use of fibre-reinforced composites (FRCs) has risen considerably across many areas of application including automotive, aerospace, naval, defence, energy and sports given their desirable specific stiffness and strength. In all these potential application areas, dynamic impact cases caused by projectile impacts are highly likely. Some examples of typical dynamic loading conditions can be generally split into two different scenarios: (i) low-velocity impacts such as movement into airborne rigid debris on runways, railway lines and automotive race tracks (1-100 m/s) and (ii) high-velocity events, e.g. caused by a flight at Mach 1-2 (300-600 m/s) of jets or intercontinental ballistic missiles through, as an example, a fragmentable hailstone cloud. Developing a full understanding of these types of dynamic loading conditions as well as projectile objects and their potential effect on an FRC's response to them is extremely important, in terms of, on the one hand, both local and global deformations, and, on the other, the visible and internal damage.

Though extensive studies have been conducted on the ballistic impact of composites with steel projectiles (see e.g. [1-10]), a

\footnotetext{
* Corresponding author at: Wolfson School of Mechanical, Electrical and Manufacturing Engineering, Loughborough University, Ashby Road, Leicestershire LE11 3TU, UK.

E-mail addresses: L.A.Coles@lboro.ac.uk (L.A. Coles), A.Roy3@lboro.ac.uk (A. Roy), sazhenkov_na@mail.ru (N. Sazhenkov), leonid-v-voronov@yandex.ru (L. Voronov), Nikhamkin@mail.ru (M. Nikhamkin), V.Silberschmidt@lboro.ac.uk (V.V. Silberschmidt).
} 
(a)

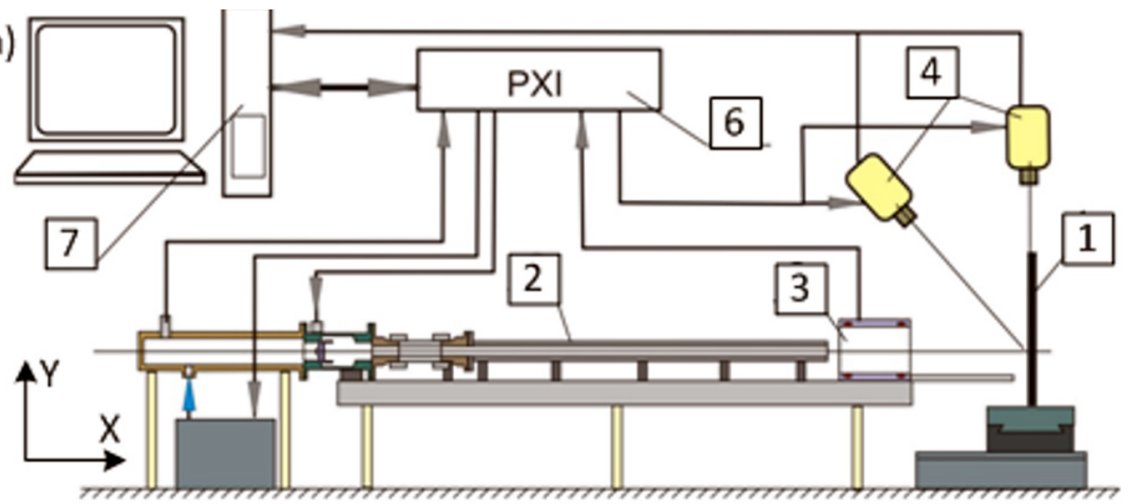

(b)

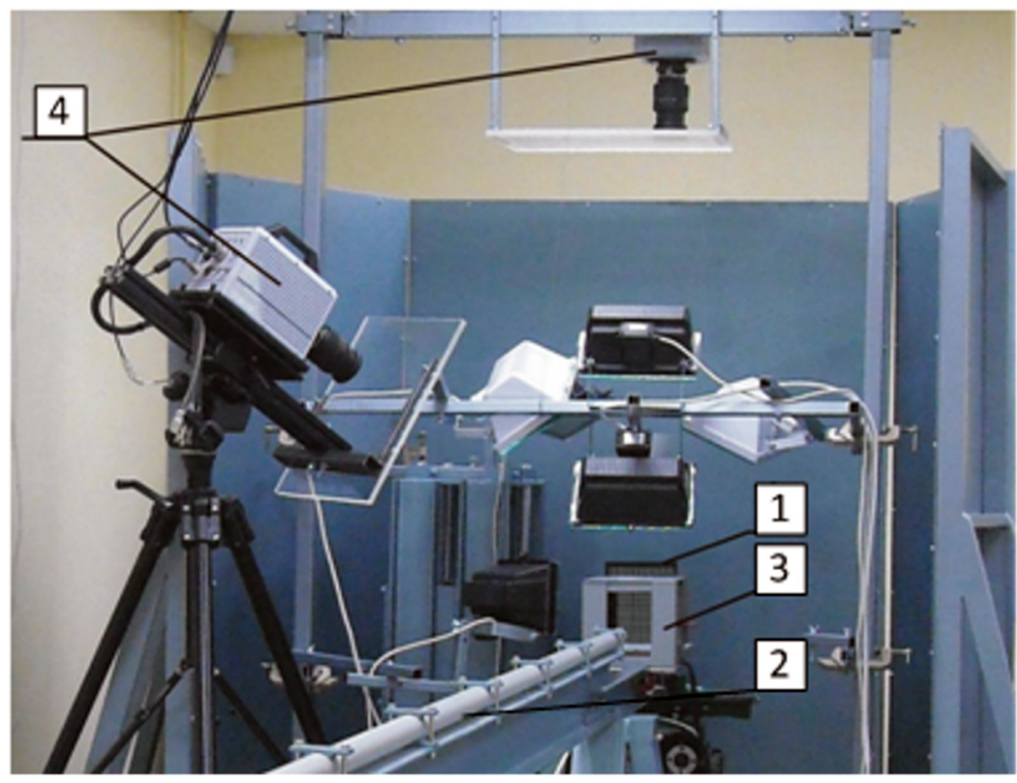

Fig. 1. Ballistic experimental apparatus: (a) schematic of setup; (b) setup with its components (1 - specimen; 2 - pneumatic gun; 3 - velocity measuring device; 4 - high-speed cameras; 5 - PXI system (National Instruments); 6 - PC).
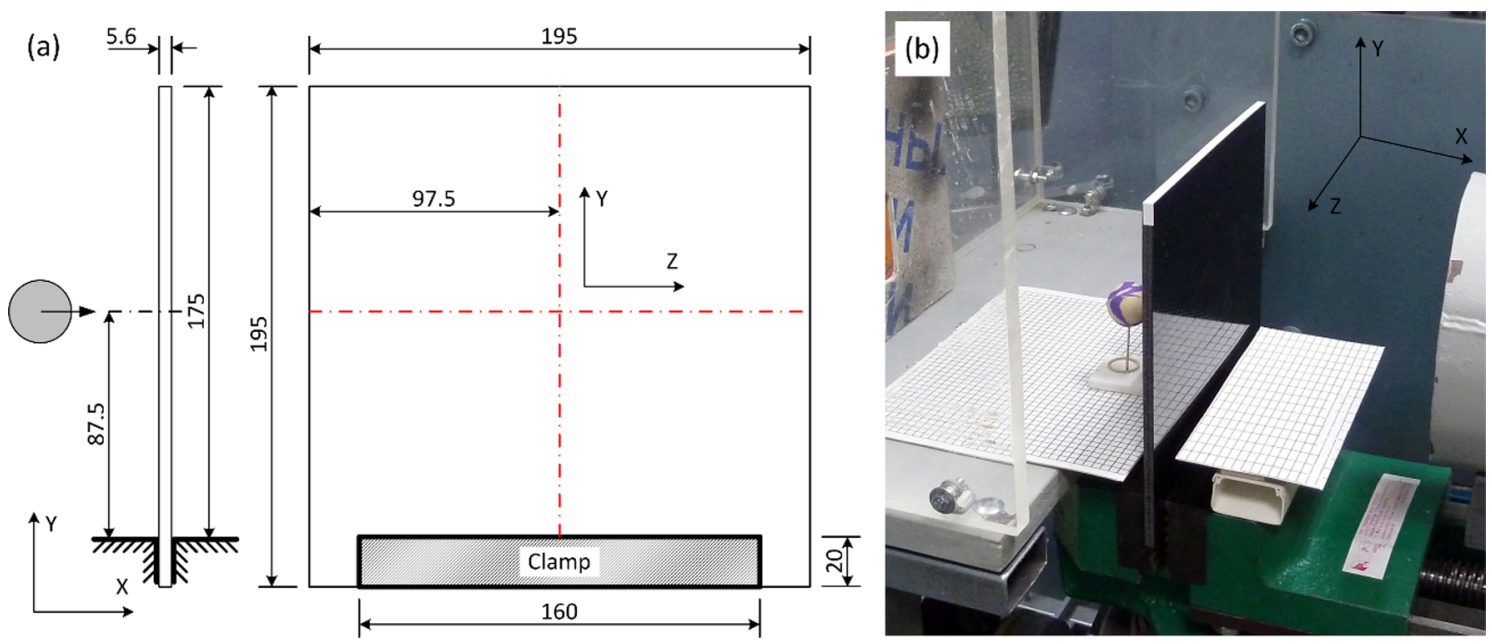

Fig. 2. Ballistic experimental cantilever fixture: (a) schematic diagram (all dimensions in $\mathrm{mm}$ ); (b) photograph. 
Table 1

Ballistic velocities and energies for steel and ice projectiles and camera configurations.

\begin{tabular}{|c|c|c|c|c|c|c|c|c|}
\hline & Damage level & Sample & $\begin{array}{l}\text { Initial velocity } \\
(\mathrm{m} / \mathrm{s})\end{array}$ & $\begin{array}{l}\text { Incident energy } \\
(\mathrm{J})\end{array}$ & $\begin{array}{l}\text { Resultant velocity } \\
(\mathrm{m} / \mathrm{s})\end{array}$ & $\begin{array}{l}\text { Resultant energy } \\
\text { (J) }\end{array}$ & $\begin{array}{l}\text { Absorbed energy } \\
(\mathrm{J})\end{array}$ & $\begin{array}{l}\text { Camera } \\
\text { configuration }\end{array}$ \\
\hline \multirow[t]{9}{*}{ Steel } & \multirow[t]{3}{*}{ Major } & D4 & 91.4 & 228.5 & -14.3 & 5.6 & 222.9 & \multirow[t]{3}{*}{ Front and top views } \\
\hline & & E3 & 91.2 & 227.5 & 12.3 & 4.1 & 223.3 & \\
\hline & & E5 & 91.8 & 230.5 & 12.0 & 3.9 & 226.6 & \\
\hline & \multirow[t]{3}{*}{ Medium } & C3 & 78.4 & 168.1 & - & - & - & \multirow[t]{3}{*}{ DIC (rear view) } \\
\hline & & D2 & 78.6 & 169.0 & - & - & - & \\
\hline & & D5 & 78.4 & 168.1 & - & - & - & \\
\hline & \multirow[t]{3}{*}{ Minor } & B2 & 59.4 & 96.5 & - & - & - & \multirow[t]{3}{*}{ DIC (rear view) } \\
\hline & & B4 & 60.0 & 98.5 & - & - & - & \\
\hline & & B5 & 59.0 & 95.2 & - & - & - & \\
\hline \multirow[t]{9}{*}{ Ice } & \multirow[t]{3}{*}{ Major } & E1 & 481.0 & 867.6 & \multirow[t]{3}{*}{ All fragmented } & - & - & \multirow[t]{3}{*}{ Front and top views } \\
\hline & & E2 & 480.0 & 864.0 & & - & - & \\
\hline & & E4 & 479.0 & 860.4 & & - & - & \\
\hline & \multirow[t]{3}{*}{ Medium } & $\mathrm{C} 2$ & 402.0 & 606.0 & \multirow[t]{3}{*}{ All fragmented } & - & - & \multirow[t]{3}{*}{ DIC (rear view)) } \\
\hline & & D1 & 403.0 & 609.0 & & - & - & \\
\hline & & D3 & 402.0 & 606.0 & & - & - & \\
\hline & \multirow[t]{3}{*}{ Minor } & A4 & 304.0 & 346.6 & \multirow[t]{3}{*}{ All fragmented } & - & - & \multirow[t]{3}{*}{ DIC (rear view) } \\
\hline & & B1 & 304.0 & 346.6 & & - & - & \\
\hline & & B3 & 303.0 & 344.3 & & - & - & \\
\hline
\end{tabular}

Table 2

Details of composite plies.

\begin{tabular}{|c|c|c|c|c|c|c|c|}
\hline \multirow[t]{2}{*}{ Ply } & \multirow[t]{2}{*}{ Description } & \multirow[t]{2}{*}{ Weave } & \multirow[t]{2}{*}{ Orientation } & \multirow[t]{2}{*}{ Density $\left(\mathrm{g} / \mathrm{m}^{3}\right)$} & \multicolumn{2}{|c|}{ Distribution } & \multirow[t]{2}{*}{ Thickness (mm) } \\
\hline & & & & & Warp & Weft & \\
\hline Surface $\times 2$ & T300 $3 \mathrm{~K}$ & $2 \times 2$ Twill & $0 / 90^{\circ}$ & 0.22 & $50 \%$ & $50 \%$ & 0.31 \\
\hline Mid (Bulking) $\times 8$ & T300 12 K & $2 \times 2$ Twill & $0 / 90^{\circ}$ & 0.63 & $49 \%$ & $51 \%$ & 0.62 \\
\hline
\end{tabular}
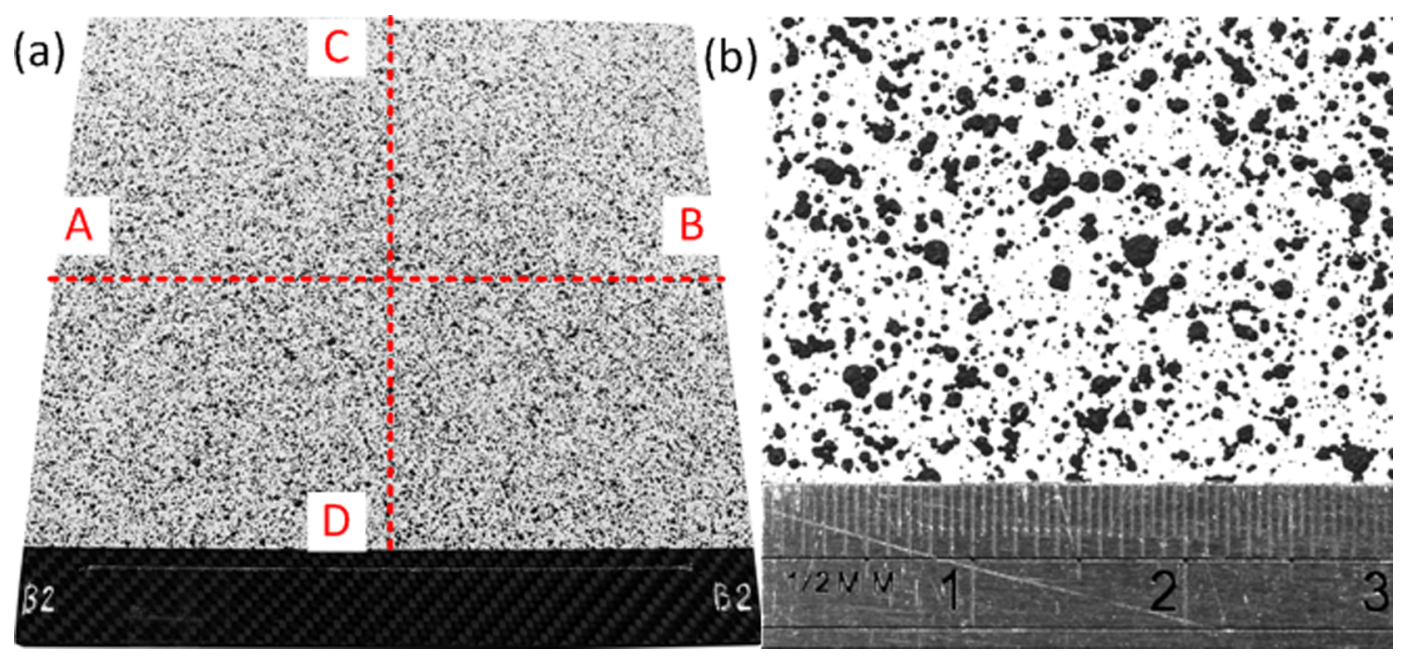

Fig. 3. Speckle patterns applied to specimens: (a) $200 \times 200 \mathrm{~mm}$ sample; (b) pattern details.

comprehensive study detailing the nature of damage due to the impact of solid and fragmenting projectiles is lacking. Typically, steel spherical projectiles are considered to remain solid upon impact (with purely elastic deformations) with the target composite material considered in this study, usually resulting in a spallation effect at the rear surface leading to delamination and tensile failure of the rear ply when complete penetration is not observed [11]. But for a similarly sized projectile made of ice, the interaction behaviour is significantly different and more complex. In recent years, effort has been made towards understanding the impact process of ice 


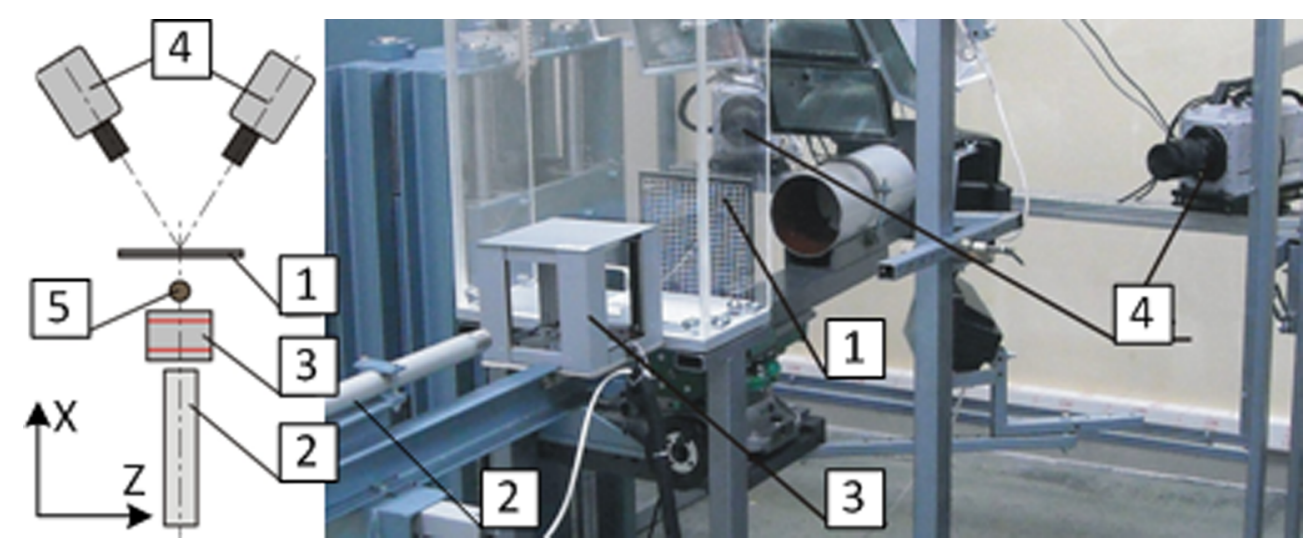

Fig. 4. Ballistic experimental apparatus with DIC configuration (rear-surface view) (1 - specimen; 2 - pneumatic gun, 3 - velocity measurement device; 4 - high-speed cameras; 5 - projectile).

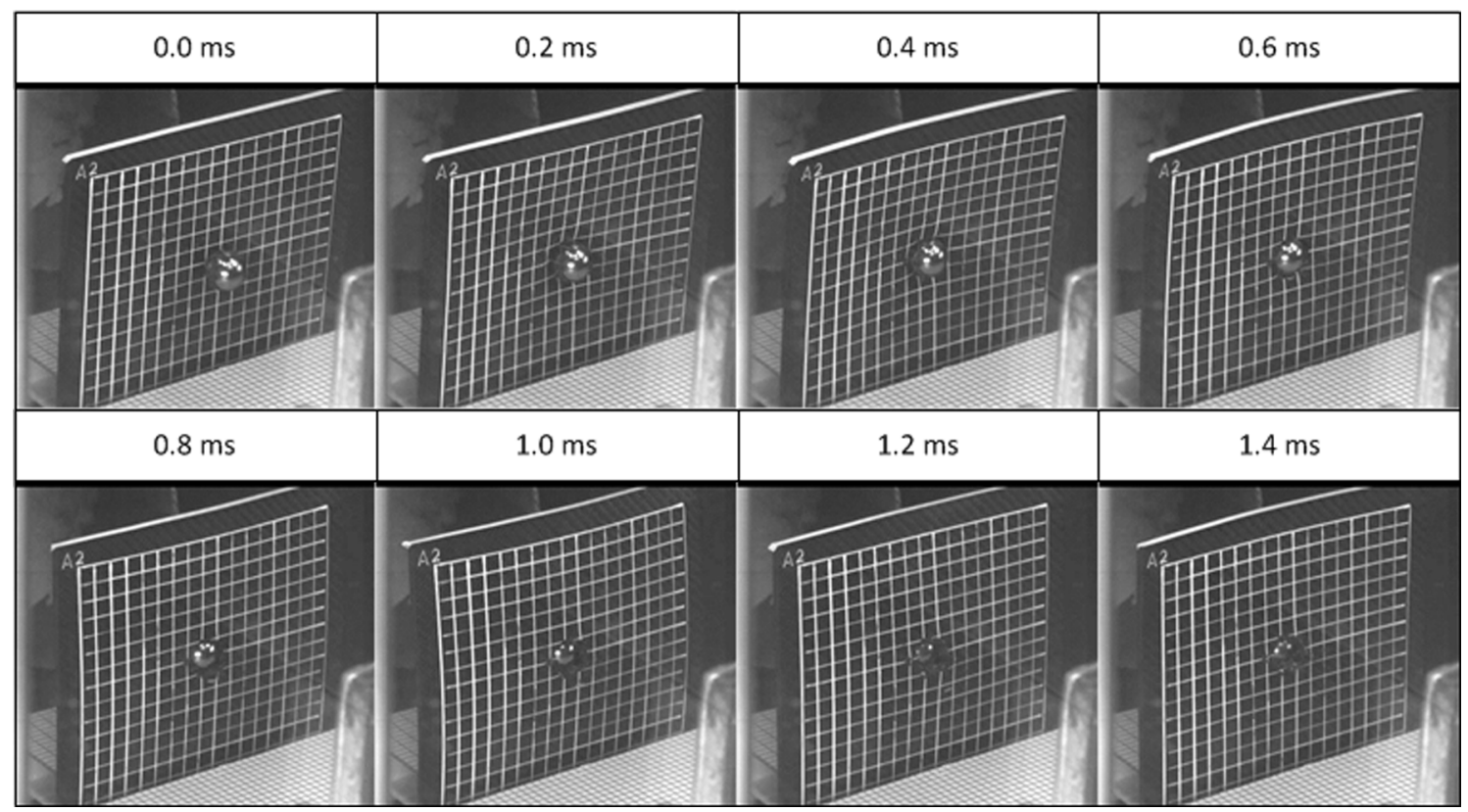

Fig. 5. Behaviour of specimen - steel impact at $90 \mathrm{~m} / \mathrm{s}$ (images of front view from high-speed video).

projectiles and its effect on carbon-fibre-reinforced polymer (CFRP) specimens considering fragmentation on impact and the resultant distribution of loading and dispersion of kinetic energy during the dynamic event. To date, there are no direct comparisons of these features with those of rigid-projectile impacts, especially in terms of deformation behaviour during the impact event. In [12], there is a reference to comparisons with the literature stating that rigid projectiles lead to more localised damage and penetrate easier thanks to the higher energy density upon impact, whereas the brittle fragmenting projectiles (ice) result in the impact energy distributed over a greater area causing an increased amount of surface and internal damage.

Early studies investigated ductile and brittle failures of ice under compression, stating that cracks form in both regimes but individual cracks propagate only in brittle cases [13-15]. It was also found that compressive strength of ice was related to the friction observed during the cracking [16], increasing with the growing strain rate [17]. It is also worth noting that during the impact process, the exact microstructure formed had no effect on the impact interaction in high-strain-rate deformation processes [18]. Many studies indicate that the peak force imposed by a fragmenting projectile scales linearly with its kinetic energy, but a time to the peak force (hence, impulse) does not show correlation to impact velocity. A more recent study [19] investigated the ice-impact process and 


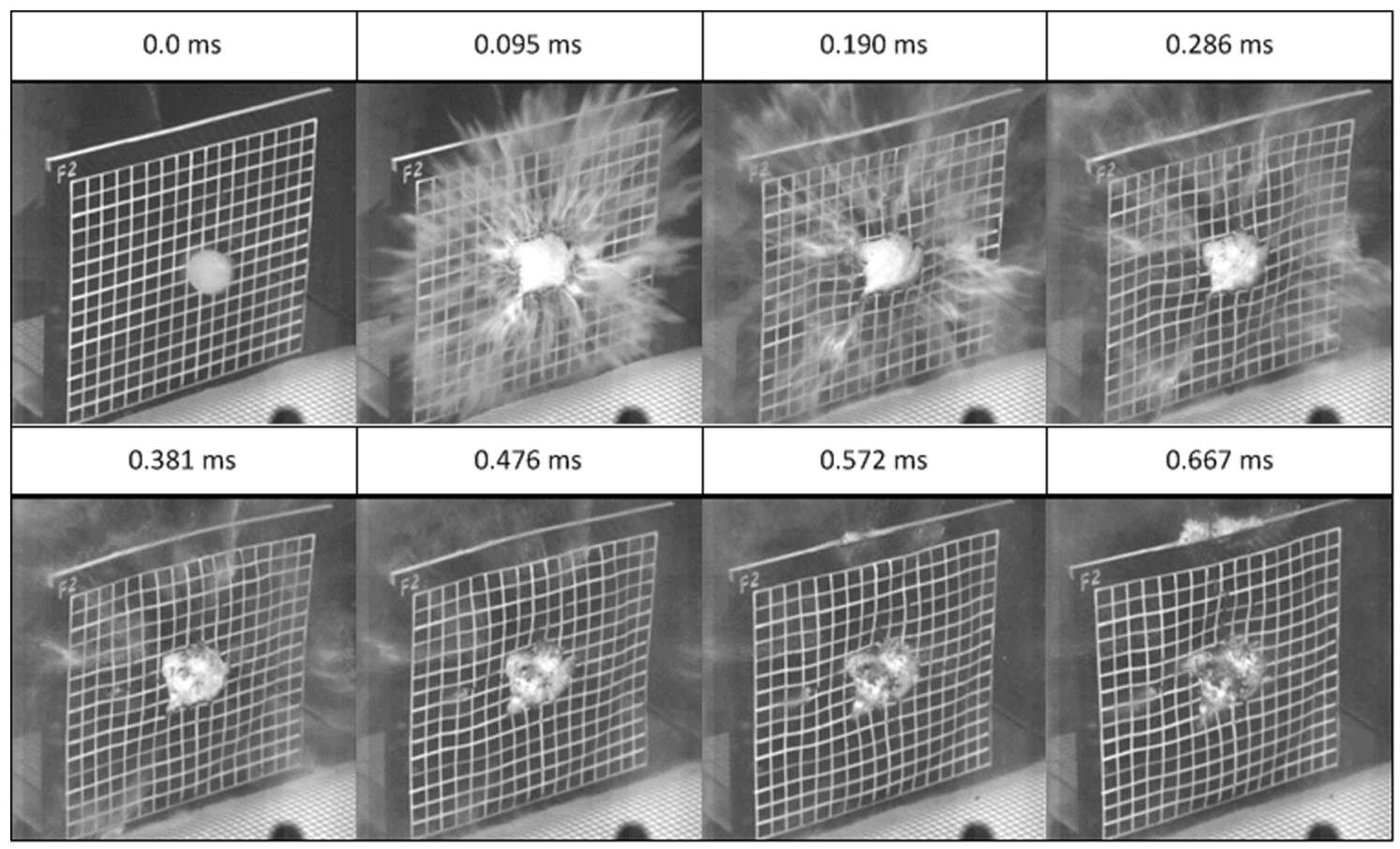

Fig. 6. Behaviour of specimen - ice impact at $480 \mathrm{~m} / \mathrm{s}$ (images of front view from high-speed video).
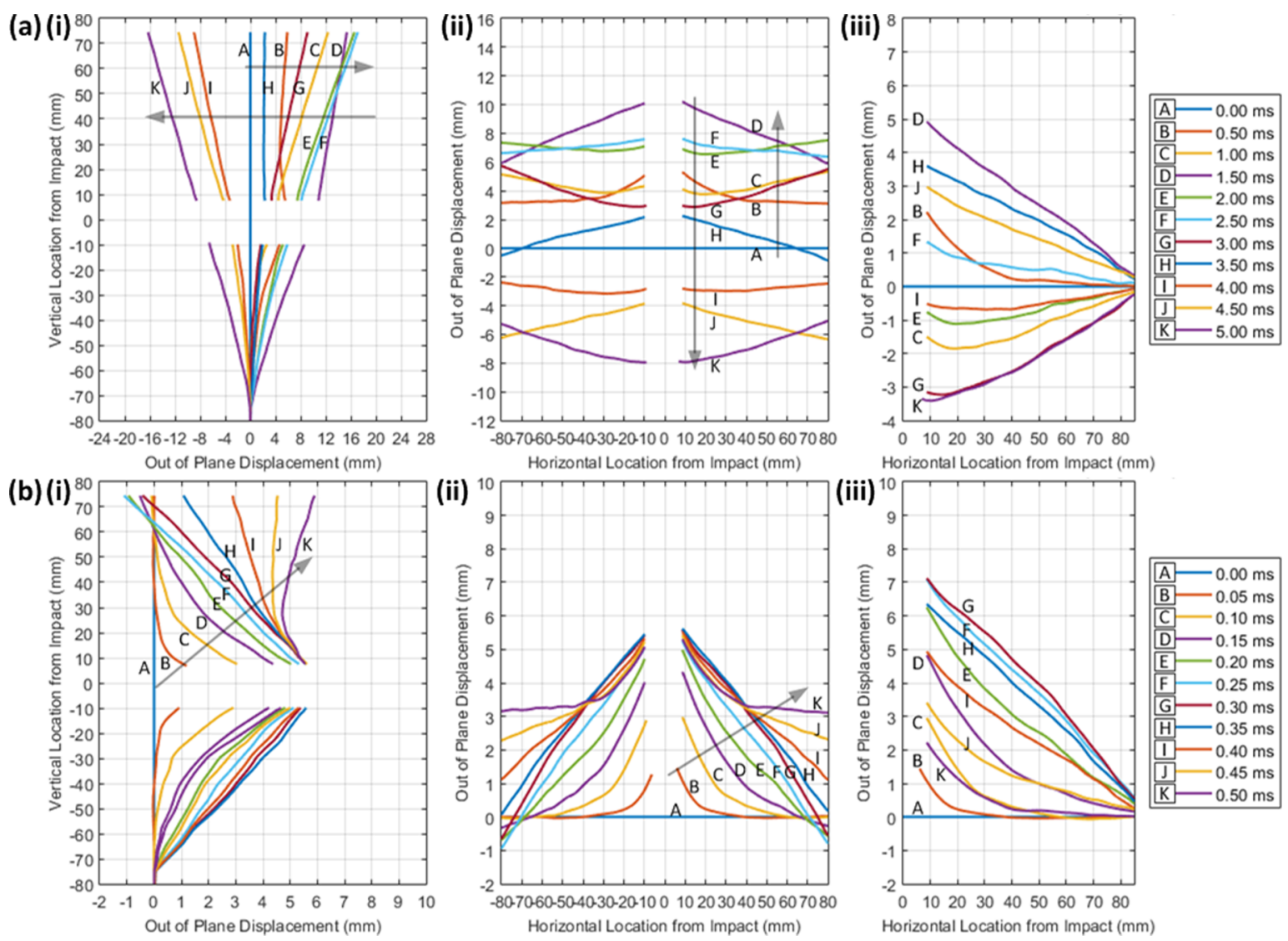

Fig. 7. Evolution of displacements of sample B2 (steel projectile with low velocity of $59.4 \mathrm{~m} / \mathrm{s}$ ): (a) 0-5 ms; (b) 0-0.5 ms, (i) vertical out-of-plane displacement; (ii) horizontal out-of-plane displacement; (iii) normalised horizontal out-of-plane displacement (half specimen). 

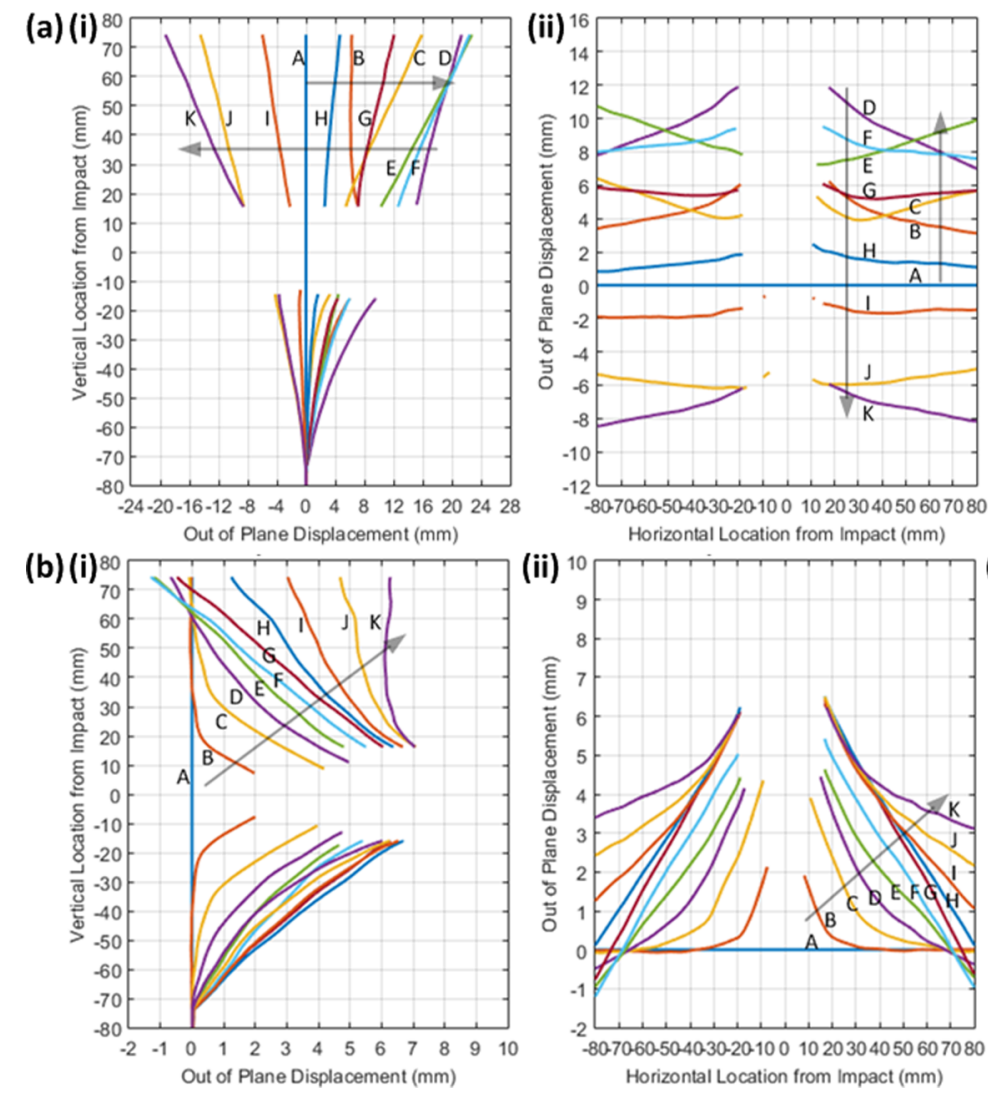
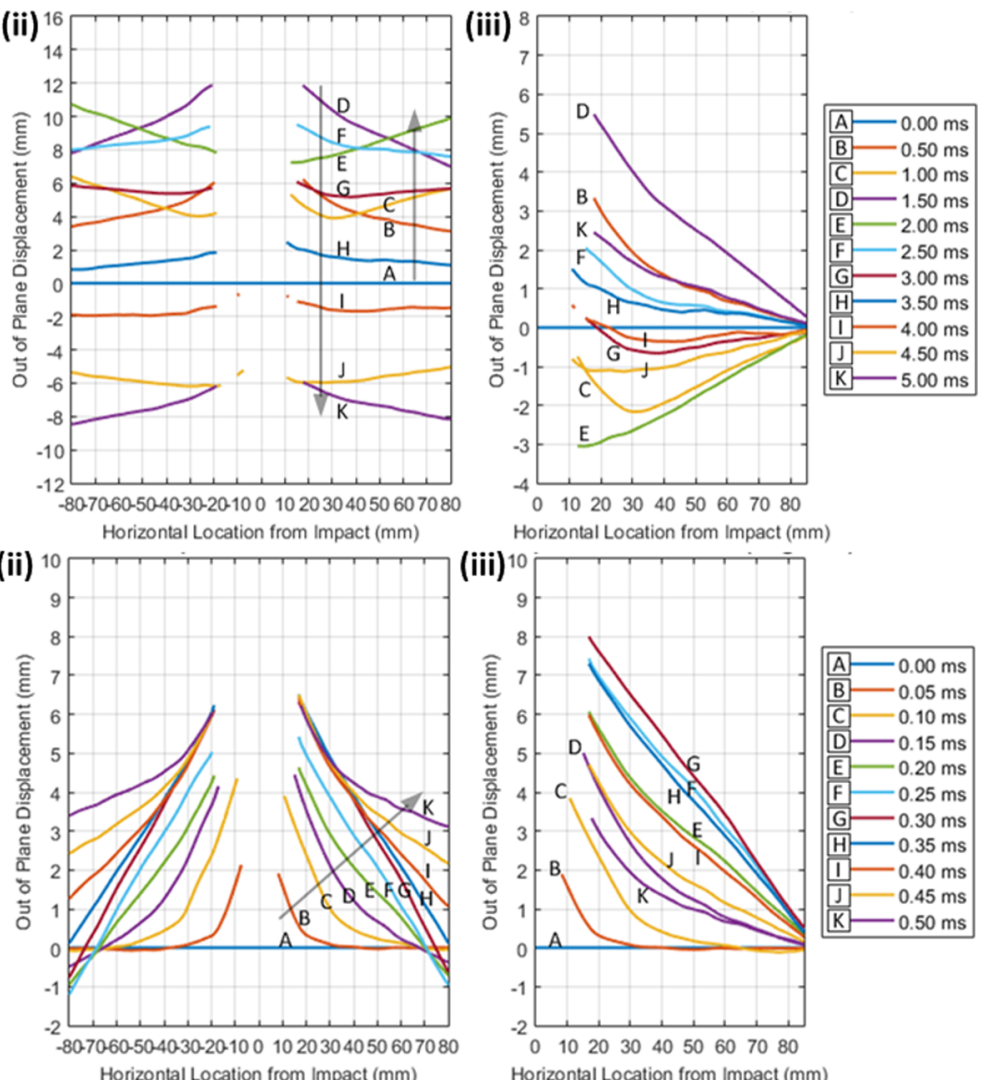

(iii)

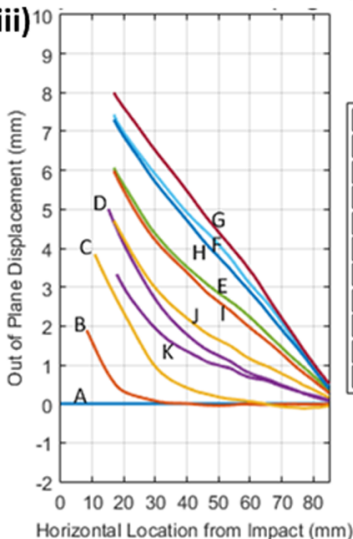

Fig. 8. Evolution of displacements of sample C3 (steel projectile with medium velocity of $78.4 \mathrm{~m} / \mathrm{s}$ ): (a) $0-5 \mathrm{~ms}$; (b) $0-0.5 \mathrm{~ms}$, (i) vertical out-ofplane displacement; (ii) horizontal out-of-plane displacement; (iii) normalised horizontal out-of-plane displacement (half specimen).

confirmed these theories, demonstrating that the fragmentation occurred at very early stages of the impact. Hence, the projectile transformed into an agglomeration of particles initiating distributed dynamic loading conditions as the impact process transitions, in contrast to rigid projectiles. It was also confirmed that the maximum peak forces were linked to the kinetic energy regardless of the size of the projectile, since the distortion energy density necessary to fragment it was negligible compared to its kinetic energy just before impact.

When considering damage in dynamic loading, the analysis of the resultant structural integrity and the extent of internal damage is usually limited to a visual inspection of external surfaces or a use of invasive techniques. While observation of external surfaces can provide some useful information, especially when combined with other analytical methods, an in-depth analysis of internal damage modes and their true extent remains a challenge [6,20-25]. With invasive techniques, such as sectioning, internal analysis is possible but additional induced undesirable damage could make analysis difficult [20,25-28].

In recent years, more suitable techniques were employed to study hidden (internal) damage, increasing greatly the opportunity for further in-depth analysis. For the case of composite materials such as CFRPs, two typical methods are usually used. The first is Csans. which can typically highlight delamination damage, generally with no real distinction of other types [25,29,30]. The second is X-ray computed tomography (CT), which provides full volumetric analysis revealing damage modes such as delamination and other main energy-dissipating intra ply mechanisms [31-34]. The volumes reconstructed with CT can be analysed to define many other typical impact features such as cone cracking [5,10].

Following these developments, especially for fragmenting projectiles such as ice, it was noted that the level of kinetic energy required to initiate internal damage was often less than that of external damage. Therefore, in some cases, structural damage could possibly go unnoticed and hidden beneath the surface [29]. Thus, the use of full volumetric X-ray tomography becomes very important for fundamental comparisons of the resultant deformation and damage caused by ballistic impacts with rigid and fragmenting projectiles.

In this paper, responses of CFRP to ballistic loading with spherical steel and ice projectiles are assessed. The aim of the study to analyse the specific differences in failure modes in the composite when subjected to impact with different projectile types. This will 

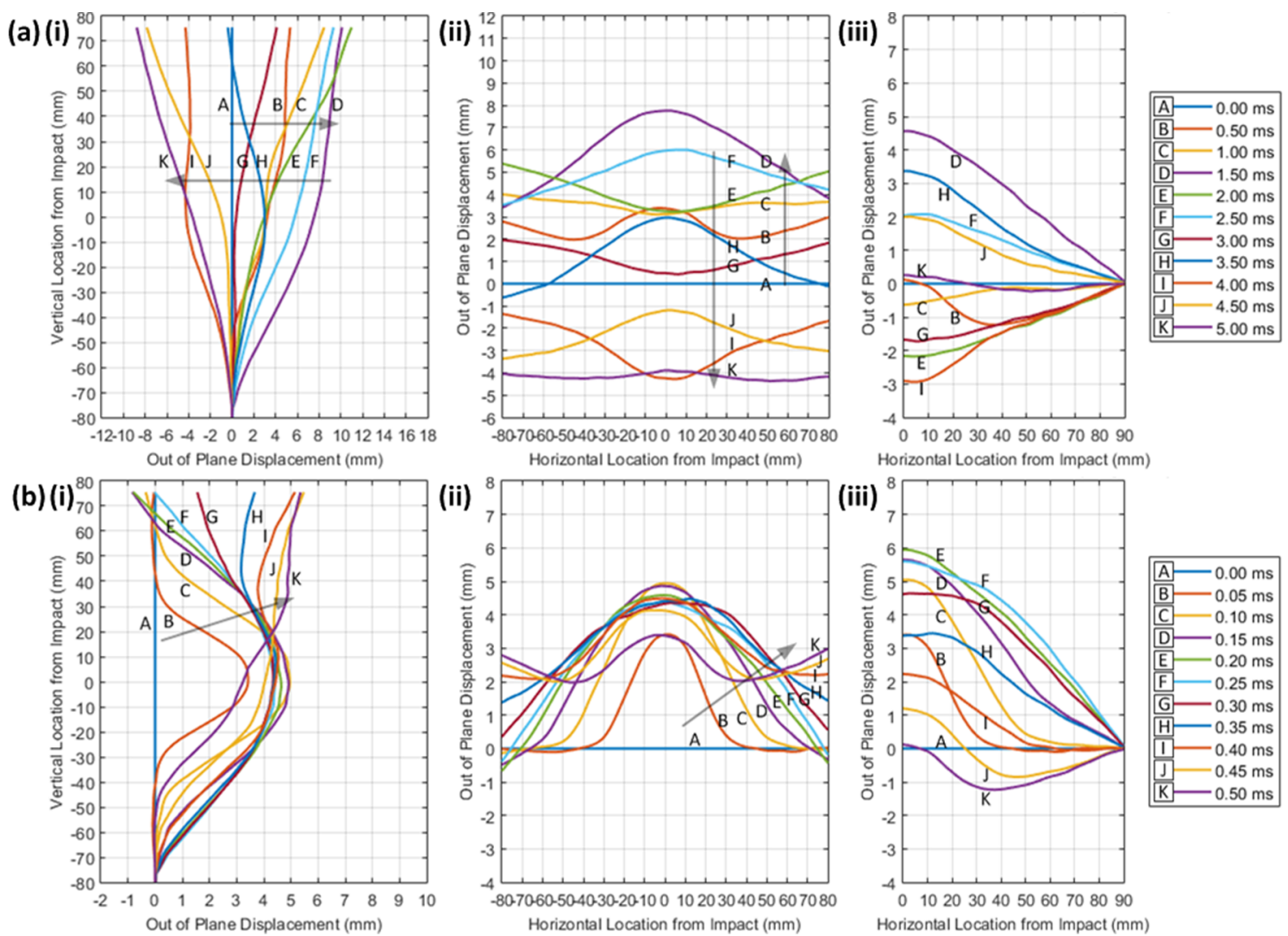

Fig. 9. Evolution of displacements of sample B1 (ice projectile with low velocity of $304 \mathrm{~m} / \mathrm{s}$ ): (a) 0-5 ms; (b) 0-0.5 ms, (i) vertical out-of-plane displacement; (ii) horizontal out-of-plane displacement; (iii) normalised horizontal out-of-plane displacement (half specimen).

facilitate a numerical approach, developed in Part II, with an aim to provide a predictive modelling capability for deformation and damage of composite for various impact events and different projectiles.

\section{Experimental studies}

\subsection{Ice and steel projectiles}

Solid steel spherical projectiles were procured with a diameter of $23.8 \mathrm{~mm}$ and nominal weight of $54.7 \mathrm{~g}$. Ice projectiles were produced via a two-shell layer freezing method to form a monolithic homogenous sphere with a diameter of $25 \mathrm{~mm}$ with a nominal weight of $7.5 \mathrm{~g}$ at a temperature of $-20^{\circ} \mathrm{C}$. The ice projectiles once produced were quickly moved into the firing position to ensure that they did not melt. Both the steel and ice projectiles were in accordance with those defined as runway debris and small hailstones, as defined by the European Aviation Safety Agency [35].

\subsection{Experimental setup and procedure.}

The investigation was performed with a ballistic experimental apparatus utilising a pneumatic gas gun as shown in Fig. 1. The CFRP specimens were aligned with the barrel as shown in Fig. 2 and clamped on one end. The direction of the projectile motion was perpendicular to the plate along the ' $x$ ' direction. Measurements of a muzzle velocity were obtained using a light gate device installed between the specimen and the barrel end. The experiment was controlled by a PC via a PXI system (National Instruments). The impact event was captured using two high-speed cameras (Photron Fastcam SA5). One of them was positioned to capture the event from an elevated front view, while the other camera was movable and was positioned to capture the plan view (as in Fig. 1) when full penetration or major damage was expected in the composite due to the impact event. When major damage was not expected, the camera was positioned behind the sample to capture deformation of its back face, which was then used to assess strains using digital 

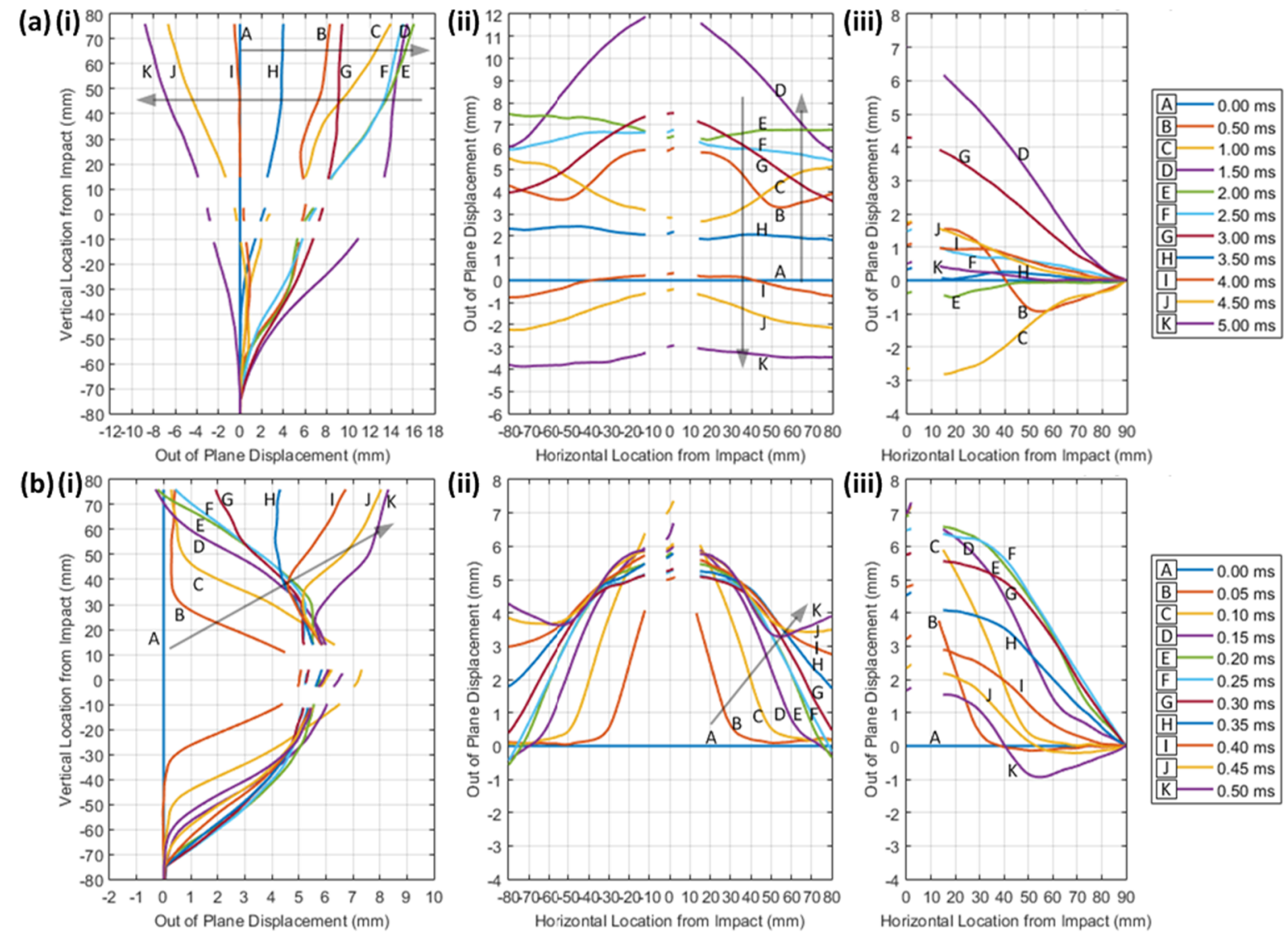

Fig. 10. Evolution of displacements of sample D1 (ice projectile with medium velocity of $403 \mathrm{~m} / \mathrm{s}$ ): (a) $0-5 \mathrm{~ms}$; (b) $0-0.5 \mathrm{~ms}$, (i) vertical out-of-plane displacement; (ii) horizontal out-of-plane displacement; (iii) normalised horizontal out-of-plane displacement (half specimen).
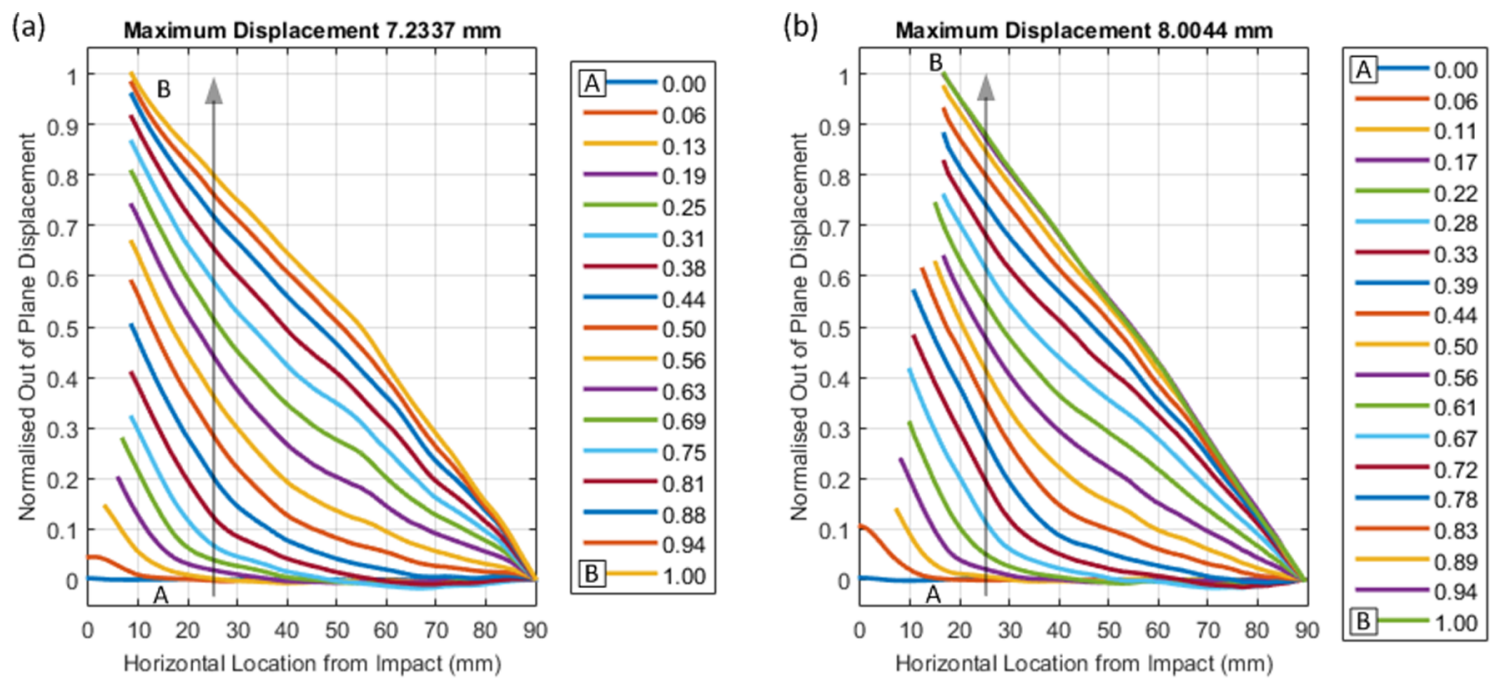

Fig. 11. Evolution of normalised displacements for steel projectiles: (a) sample B2, low velocity of $59.4 \mathrm{~m} / \mathrm{s}$; (b) sample C3, medium velocity of $78.4 \mathrm{~m} / \mathrm{s}$. 

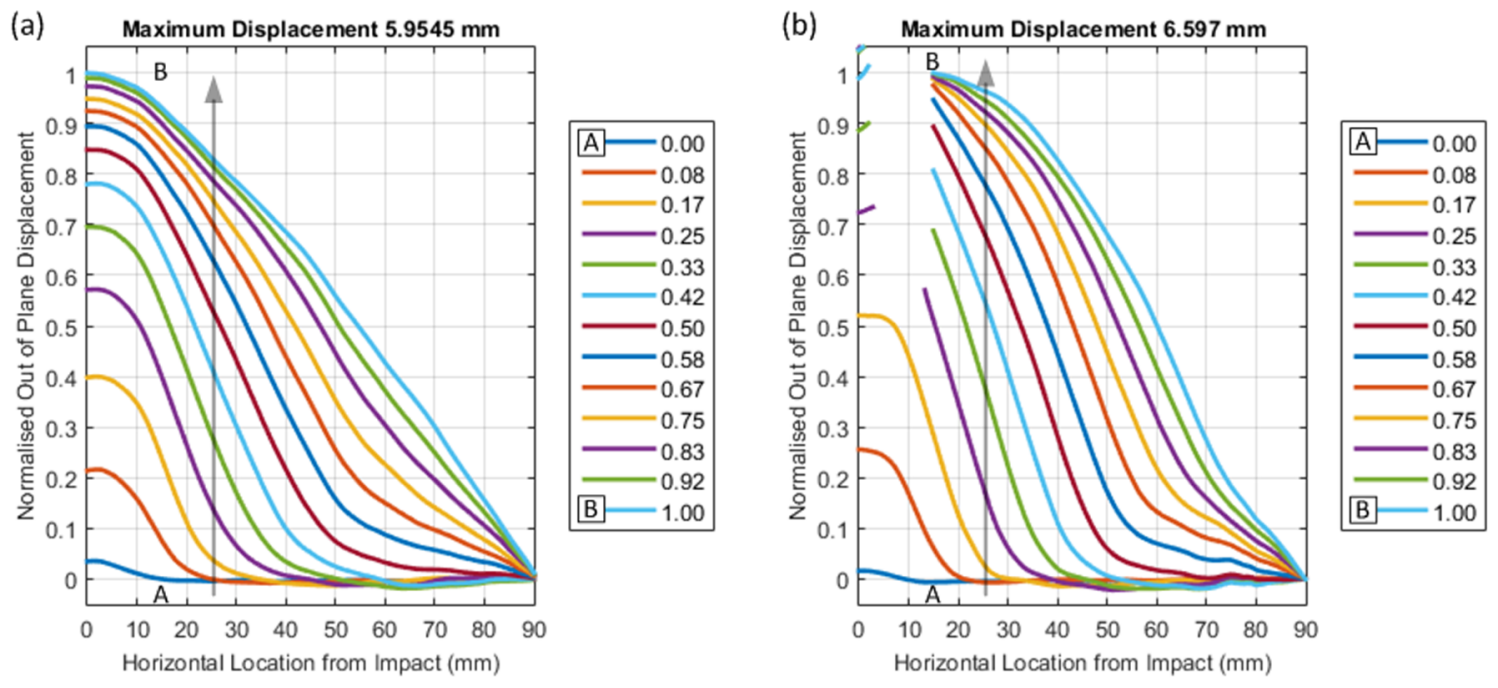

Fig. 12. Evolution of normalised displacements for ice projectiles: (a) sample B1, low velocity of $304 \mathrm{~m} / \mathrm{s}$; (b) sample D1, medium velocity of $403 \mathrm{~m} / \mathrm{s}$.

Table 3

Maximum and normalised out of plane displacements in ballistic impacts with steel and ice projectiles.

\begin{tabular}{|c|c|c|c|c|}
\hline & Damage level & Sample & Max out of plane displacement (mm) & Time till max displacement (ms) \\
\hline \multirow[t]{9}{*}{ Steel } & Major & D4 & - & - \\
\hline & & E3 & - & - \\
\hline & & E5 & - & - \\
\hline & Medium & C3 & 8.00 & 0.30 \\
\hline & & D2 & 8.88 & 0.27 \\
\hline & & D5 & 7.59 & 0.30 \\
\hline & Minor & B2 & 7.23 & 0.27 \\
\hline & & B4 & 7.36 & 0.27 \\
\hline & & B5 & 7.26 & 0.27 \\
\hline \multirow[t]{9}{*}{ Ice } & Major & E1 & - & - \\
\hline & & E2 & - & - \\
\hline & & E4 & - & - \\
\hline & Medium & $\mathrm{C} 2$ & 6.63 & 0.18 \\
\hline & & D1 & 6.60 & 0.20 \\
\hline & & D3 & 6.42 & 0.15 \\
\hline & Minor & A4 & 5.35 & 0.22 \\
\hline & & B1 & 5.95 & 0.20 \\
\hline & & B3 & 5.88 & 0.20 \\
\hline
\end{tabular}

image correlation (DIC).

Three sets of impact velocities were chosen for each type of projectile in preliminary tests to have three levels of impact intensity related to principally different damage levels, denoted here as minor, medium and major. For solid steel projectiles, the impact velocities were $58 \mathrm{~m} / \mathrm{s}, 78 \mathrm{~m} / \mathrm{s}$ and $90 \mathrm{~m} / \mathrm{s}$, corresponding to impact energies of approximately $97 \mathrm{~J}, 168 \mathrm{~J}$ and $228 \mathrm{~J}$, respectively. For ice projectiles, the impact velocities were $300 \mathrm{~m} / \mathrm{s}, 400 \mathrm{~m} / \mathrm{s}$ and $480 \mathrm{~m} / \mathrm{s}$ (corresponding impact energies - appr. $346 \mathrm{~J}$, $607 \mathrm{~J}$ and $864 \mathrm{~J}$, respectively). A full breakdown of the test parameters and high-speed camera configurations are listed in Table 1 (negative values of the resultant velocity refer to a projectile, which rebounded off the target specimen). To assess the post-impact (resultant) velocity of the solid steel projectile, high-speed-camera data was used when positioned to capture the plan view (as shown in Fig. 1). For cases where medium and minor damage was expected with the camera positioned at the rear of the sample for DIC, no resultant velocity of the steel projectiles was measured. Each experiment was repeated three times for each combination of parameters for consistency and repeatability. 


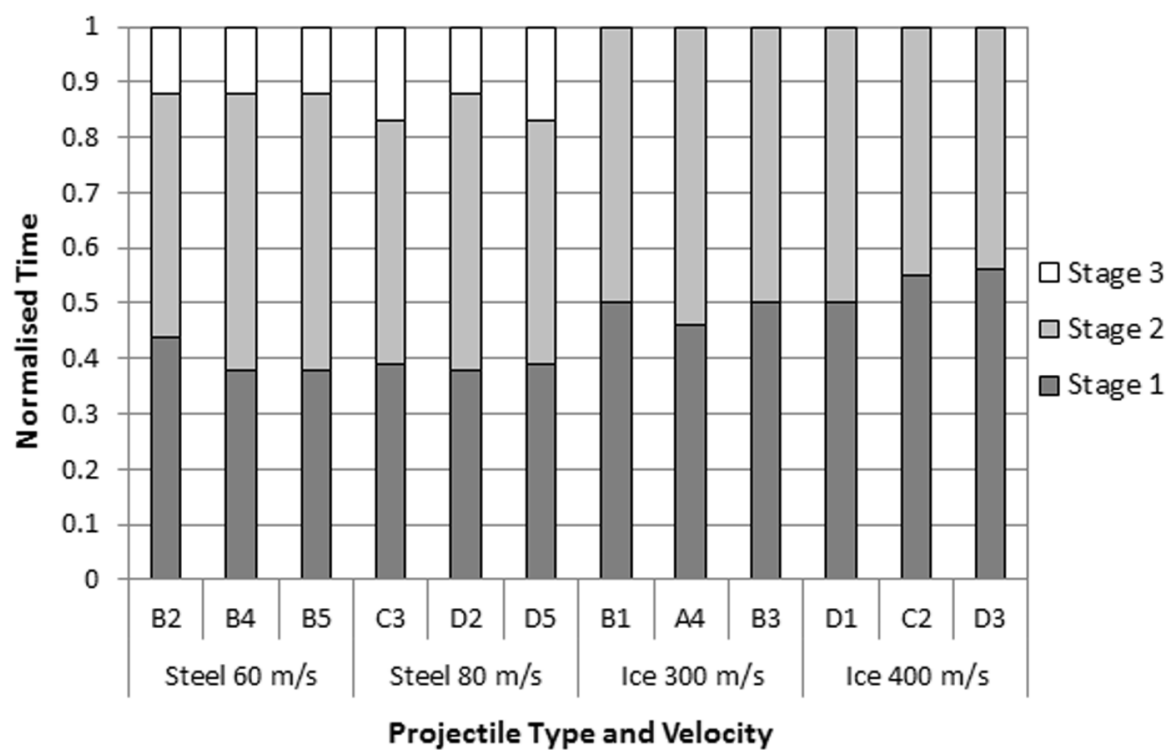

Fig. 13. Comparison of stages of deformation for different projectile types and velocities.

\subsection{Composite panels}

The CFRP specimens were fabricated from 10 plies of carbon fibre fabric, which were pre-impregnated with a toughened epoxy matrix (IMP530R). The laminate consisted of 2 surface plies and 8 central bulking plies arranged in a 0/90 layup configuration; full details of the layup are shown in Table 2.

All specimens were manufacture in an autoclave, cured at $120^{\circ} \mathrm{C}$ with a $1.5^{\circ} \mathrm{C} / \mathrm{min}$ ramp rate and a soak time of $160 \mathrm{~min}$ at a pressure of $90 \mathrm{PSI}$ in a vacuum. The resulting composite specimens had a nominal total thickness of $5.76 \pm 0.02 \mathrm{~mm}$ and a density of $1600 \mathrm{~kg} / \mathrm{m}^{3}$ with a fibre volume fraction of approx. $47 \%$. Average tow dimensions were measured to be $2.7 \mathrm{~mm} \times 0.3 \mathrm{~mm}$ with a fibre diameter of approximately $7 \mu \mathrm{m}$. Overall, each specimen had dimensions of $200 \mathrm{~mm} \times 200 \mathrm{~mm}$.

\subsection{Strain and deformation measurements}

Digital Image Correlation was used to analyse displacement and strains in the specimen with images obtained with the high-speed cameras. The VIC-3D (Correlated Solutions) system software was used to perform DIC studies. A speckle pattern of approximately 2 to 6 pixels in size was applied to the sample surface (Fig. 3) based on suggestions in prior studies [36]. Measurements made along lines $\mathrm{AB}$ and $\mathrm{CD}$ (Fig. 3) were used to assess deformations.

A high-speed photography system consisting of 2 cameras (Photron SA5 Photron USA, Inc., CA, USA) was used to capture the ballistic impact events. For DIC analysis, images were captured using the rear camera recorded at 60,000 fps (Fig. 4).

\subsection{X-ray computed tomography}

Damage within the impacted specimens was assessed post-experimentation using a Metris $160 \mathrm{H}-\mathrm{XT}$ XCT system. Each scan was conducted at $140 \mathrm{kV}$ and $130 \mu \mathrm{A}$ using a tungsten target, with 2650 radiography projections (X-ray images) taken over the $360^{\circ}$ rotation of each specimen at an exposure time of $500 \mathrm{~ms}$. The total volume scanned for each specimen was $180 \times 140 \times 20 \mathrm{~mm}^{3}$ at a resolution of $97 \mu \mathrm{m}$. The reconstructed scan volumes were analysed using the commercial VGStudio Max software.

\section{Results and discussion}

\subsection{Composite response under impact}

The sequence of images, obtained from the front-facing camera, for the impact case with the highest energy is shown in Figs. 5 and 6 for the solid and ice projectiles, respectively. The ballistic response to the ice impact (Fig. 6) demonstrates that the projectile initially indented into the specimen before fragmenting; following this, widespread delamination of the top plies occurred. In 


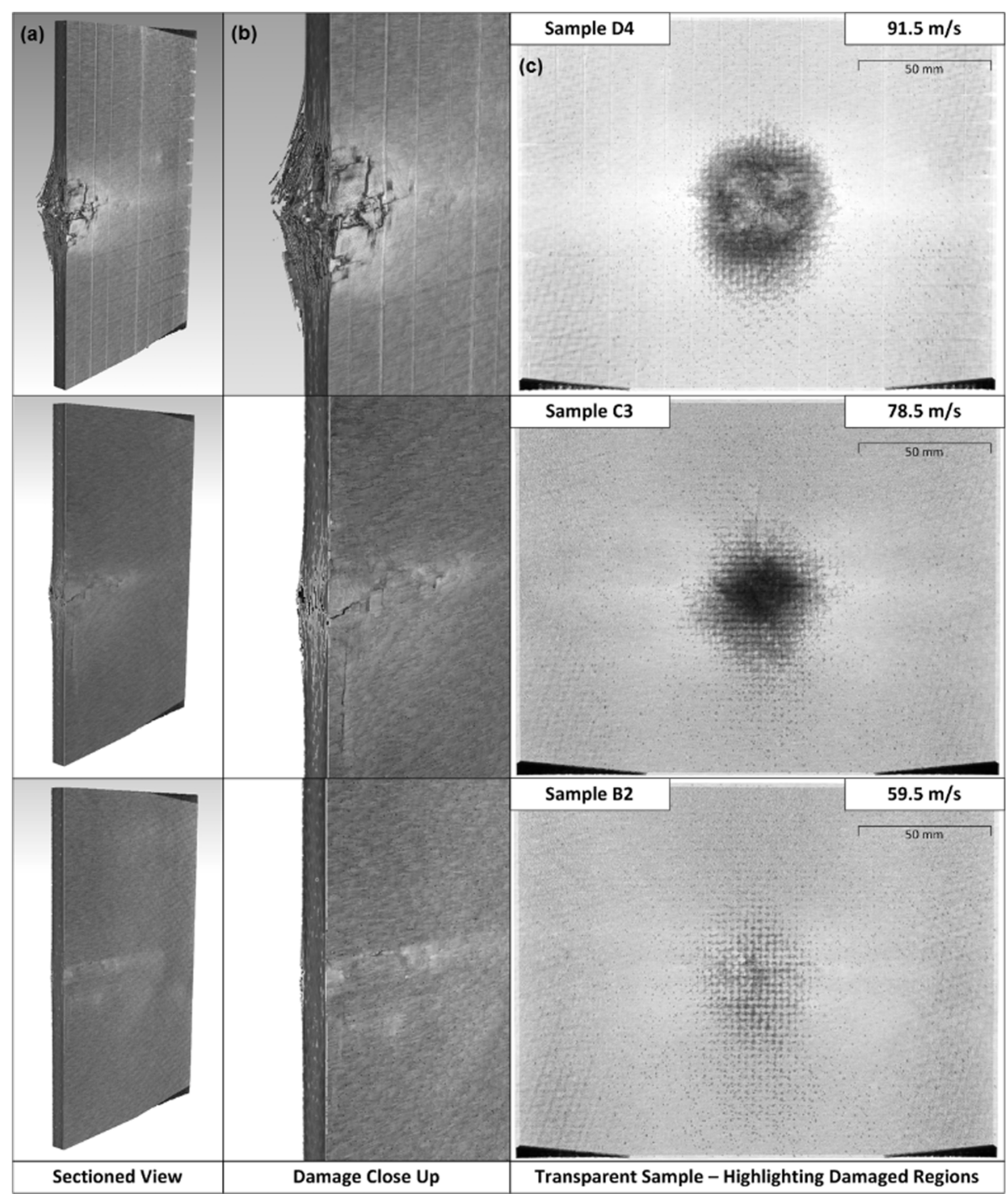

Fig. 14. Effect of velocity on damage caused by steel projectiles, 3D analysis: (a) full-section view; (b) close up; (c) through-thickness damage cloud.

contrast, the steel projectile penetrated the target initiating localised damage with delamination at the exit/rear face of the composite specimen (Fig. 5). Thus, our initial observations indicate that steel projectile leads to localised damage, whereas the ice one induces a local-to-global damage in the composite.

\subsection{Deformation analysis}

To analyse the evolution of deformation of the specimen, measurements across a vertical and horizontal lines ( $\mathrm{AB}$ and $\mathrm{CD}$ in Fig. 3) were implemented for time increment starting at $t=0$, corresponding to the moment of projectile making the first contact with the target. To analyse the true deformation of the plate, global displacements were removed from the $A B$ line scan by setting the free edges of each line section to the baseline (i.e. zero displacement). Thus, any non-zero displacement essentially represents the localised deformation in the plate caused by the projectile impact for a specific time increment. For line scans along $\mathrm{CD}$, the bottom fixation point was set to zero for each time increment (as it was clamped). The localised behaviour was normalised with the maximum absolute displacement for the chosen line at each measured time increment. This allows comparisons for different loading conditions. It should be noted that when the centre point was available from measurements it was used to find the maximum displacement, and when not available (in the case of extreme damage due to perforation by the projectile), the closest available point 


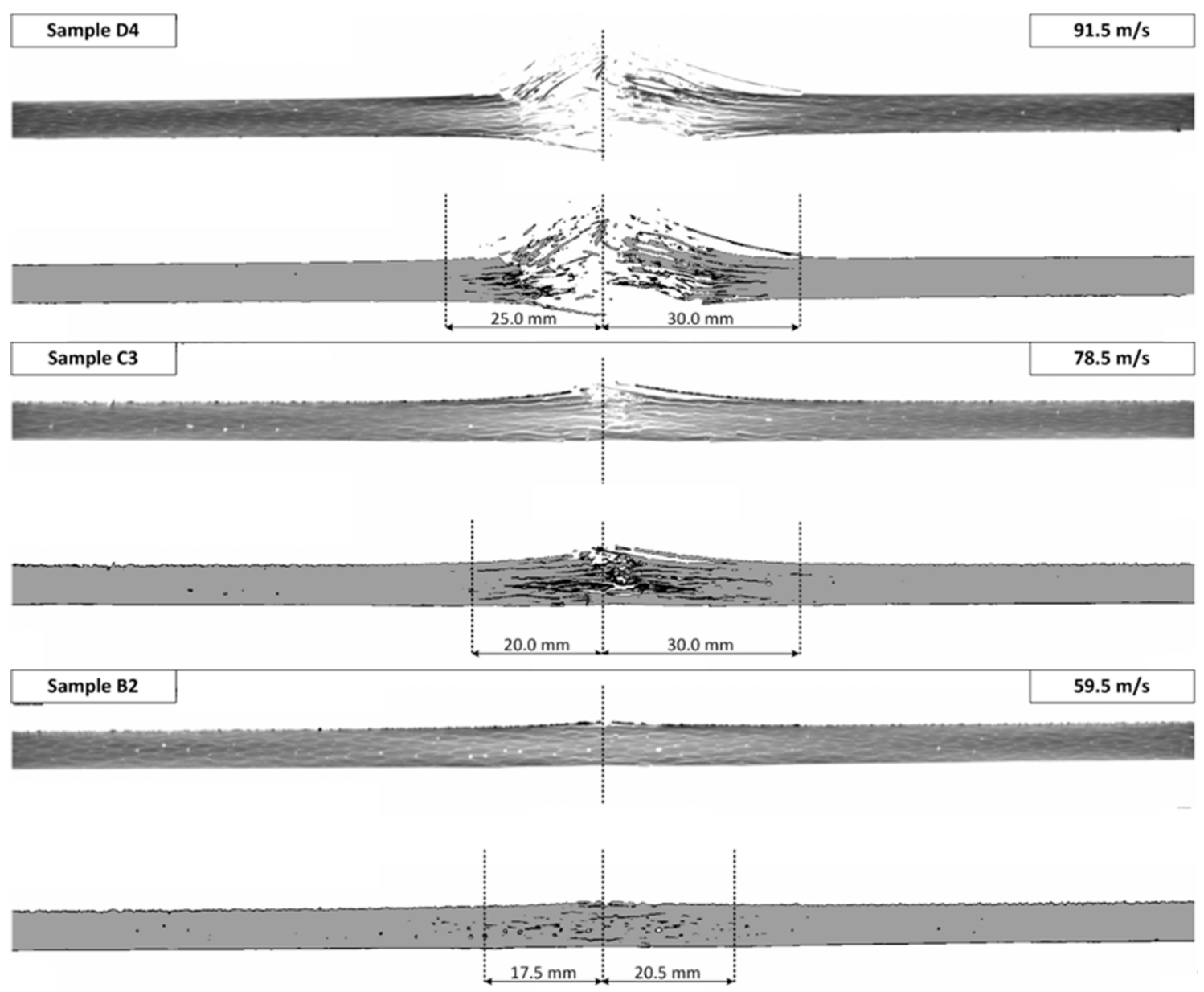

Fig. 15. Effect of velocity on damage caused by steel projectiles, 2D analysis along AB (see Fig. 3a).

along the horizontal line scan was chosen for this.

The character of deformations for low- and mid-velocity impacts of the composite with steel and ice projectiles are shown in Figs. 7-8 and Figs. 9-10, respectively. In each figure, images (a) demonstrate the global displacement over 5 ms in increments 0.5 ms with images (b) presenting only the first $0.5 \mathrm{~ms}$ in temporal increments of $0.05 \mathrm{~ms}$, thus showing the initial stages of the impact. Images (i) indicate the out-of-plane displacement along $\mathrm{CD}$, with (ii) presenting the displacement along $\mathrm{AB}$, and (iii) -adjusted horizontal line plots along $\mathrm{AB}$ with the free edges displacement coinciding for all the temporal increments (zero displacement, as discussed above).

Damage observed at the rear surface of the specimens (enough to affect the speckle pattern and DIC) occurred much earlier in the case of the solid projectile (steel), manifested also by the lack of data in some graphs. This was likely due to the almost instantaneous fragmentation of the ice projectile on impact, causing more widely distributed loading and, therefore, a longer impact duration even at higher impact energies. The increased impact duration together with the physical destruction of the ice projectile assisted the transfer and dissipation of kinetic energy within the specimens, resulting in differences in the level of out-of-plane displacements and the appearance of damage at the rear surface.

Impacts with ice projectiles (Figs. 9 and 10) demonstrated a well-defined indentation deformation of the specimens before a transition to global flexural bending with fragmentation of the projectile. An increase in impact energy led to increased global flexural bending after this fragmentation.

For the solid (steel) projectiles, the specimen's deflection mode was local indentation leading to failure at the rear surface, resulting in a gap in the obtained data due to damage to the speckle pattern. This was followed by transitions to a simple mode of global flexural bending of the specimens horizontally and cantilever bending vertically. In contrast, destruction of the ice projectiles 

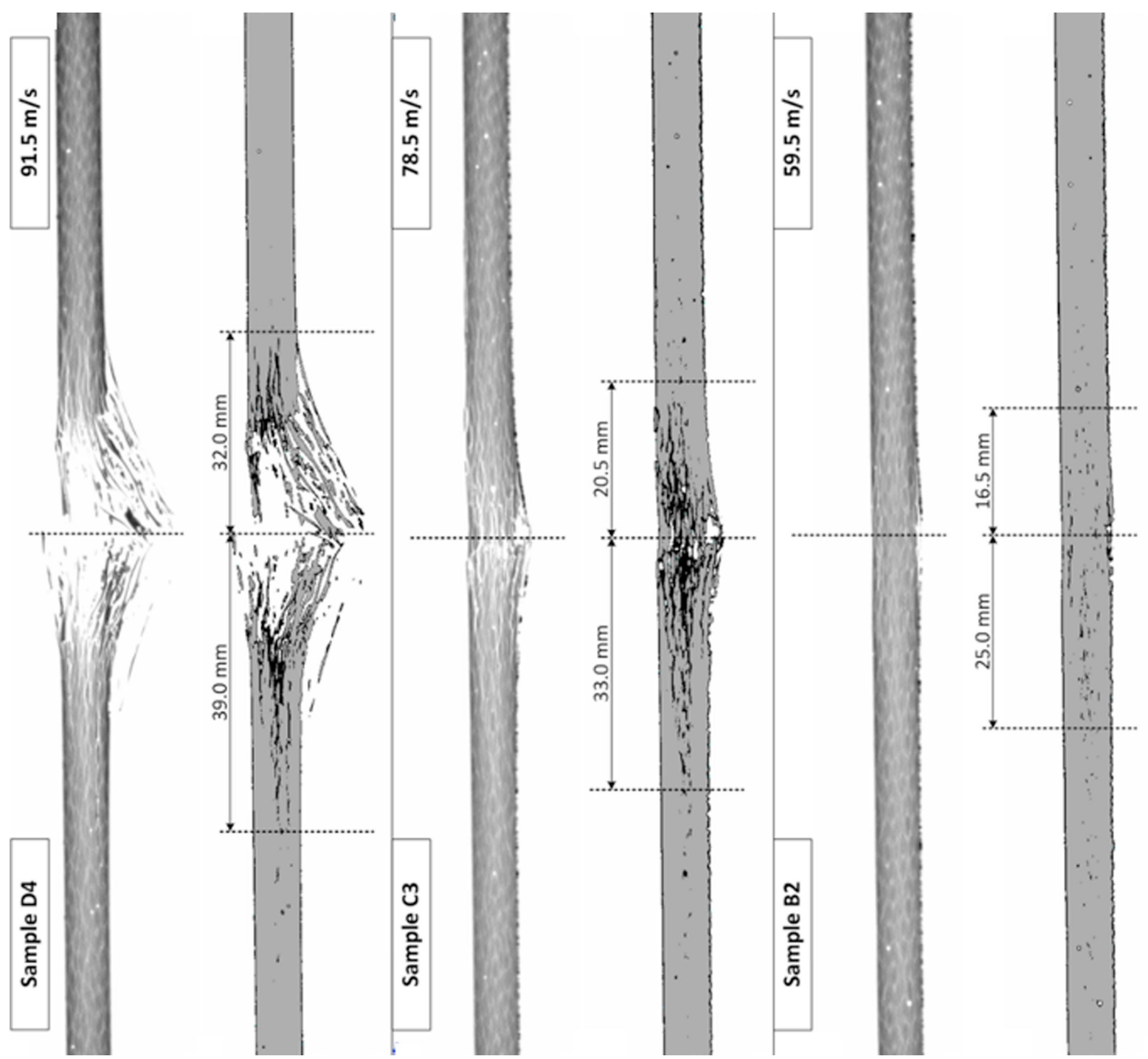

Fig. 16. Effect of velocity on damage caused by steel projectiles, 2D analysis along CD (see Fig. 3a).

on contact in impact resulted in the local indentation of the specimen followed by a transition to more widespread loading, causing reduced failures at the rear surface and complex modes of bending during the impact.

The earlier stages of ballistic-impact loading conditions offer the greatest insight: Fig. 11 demonstrates the responses to the steelprojectile impacts and Fig. 12 - the ice-projectile ones. In each figure, the left plots present the normalised out-of-plane deformation for the low-velocity impact, and the right - for the medium-velocity impact. Here, to allow better comparability, the respective moments of time are normalised with the time to the maximum out-of-plane displacement.

A summary of the maximum out-of-plane displacements and respective times is given in Table 3.

By considering all available time increments in Figs. 11 and 12, three stages of deformation can be defined for each projectile type and velocity to analyse their impact behaviour. Stage 1 corresponds to local indentation, with parts of the surface remaining at 0 displacement (within a range of $\pm 0.25 \mathrm{~mm}$ ), Stage 3 corresponds to global flexural bending, while Stage 2 is defined as transitional between Stages 1 and 3. The stages of deformation are shown in Fig. 13.

Stage-3 deformations for the solid projectiles were clearly evident when approaching the normalised time 1.0; however, this was not the case for the ice projectiles. The indentation stage (Stage 1) for them was marginally longer, as a result of the higher impact energy of the ice projectiles. The transitional stage (Stage 2) appears to be almost identical for both cases, with any variation or increase in the duration of the stage for the ice projectiles resulting from a more complex interaction of distributed loading. Finally, 


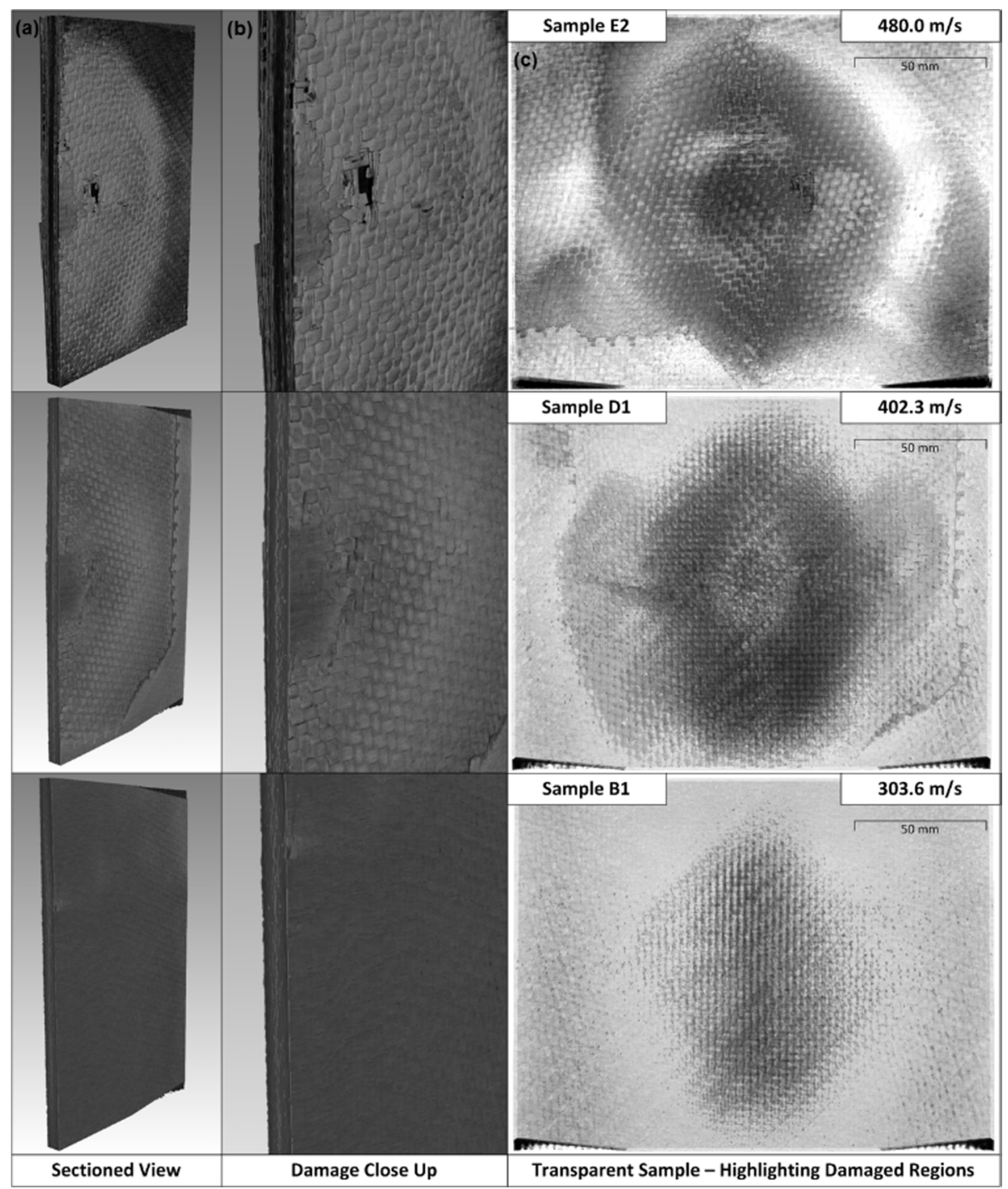

Fig. 17. Effect of velocity on damage caused by ice projectiles, 3D analysis: (a) full-section view; (b) close up; (c) through-thickness damage cloud.

with solid projectiles causing greater localised deformation, the specimens reached global flexural bending (Stage 3) sooner than that for the fragmenting projectiles.

\subsection{Damage analysis}

For impact with solid projectiles, Fig. 14 presents the comparison of damage between the different impact velocities.

With a growing impact velocity, though there was an overall increase in damage (in compressive damage at the impact point and tensile failure at back face), the effective damaged area was nearly contained in a localised zone. 2D sectional views, presented in Figs. 15 and 16, confirm that the size of the damage area remained similar, with increasing penetration damage at higher impact energies. The vertical CD sections are shown in Fig. 16 also demonstrate the effect of the cantilever clamping method, as the damage extended down towards the bottom of the sample where the fixture was located.

Damage in the composite caused by the fragmenting (ice) projectiles is shown in Fig. 17. With a rising impact energy, an increase 

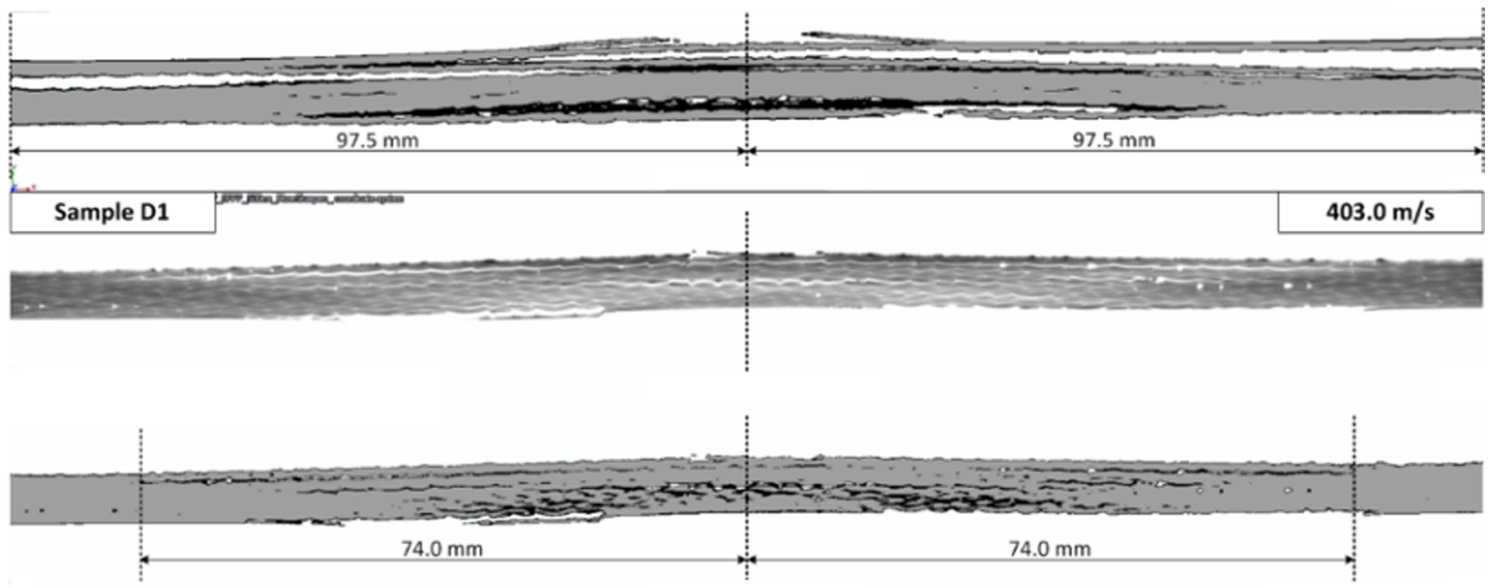

Sample B1

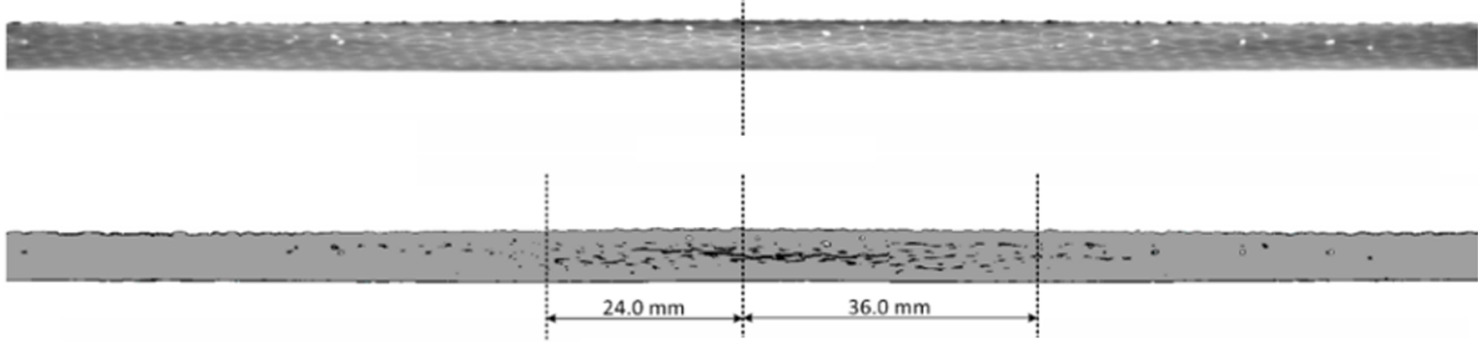

Fig. 18. Effect of velocity on damage caused by steel projectiles, 2D analysis along AB (see Fig. 3a).

in surface damage was observed. In contrast to the solid projectiles, the ice ones initiated significant internal damage along with external damage in the composite material.

Also, in contrast to damage due to solid-projectile impact, ice projectiles caused only limited penetration with partial indentation and significant de-lamination of the first few plies of the specimen from its front surface. This was confirmed by the 2D sectional views as shown in Figs. 18 and 19.

Measurements of the main dimensions and areas of damage clouds formed by ballistic impacts with various loading conditions could form a basis for quantitative comparative analysis for the two studied types of projectiles. Table 4 contains a summary of the horizontal and vertical spread of the observable damage (based on the X-ray CT data) and the estimated total damaged area for the steel and ice impacts on the composite evaluated from Figs. 15-16 and 18-19.

The averaged data from Table 4 is presented in Fig. 20, showing a translation of an increase in impact energy into a growth of damage sustained by composite specimens. For the rigid projectile, this trend is less prominent than that for the fragmenting one. This can be explained by the observed transition from a localised indentation to the global distributed loading as the projectile fragmented.

\section{Conclusions}

Impacts of CFRP with solid and fragmenting projectiles of similar size demonstrated that deformations in the composite were localised for steel projectiles, whereas ice ones led to global flexural bending of the plate. Increased damage at the rear surface of the specimens occurred more for solid projectiles than fragmented ones. This was likely due to the almost instantaneous fragmentation of 


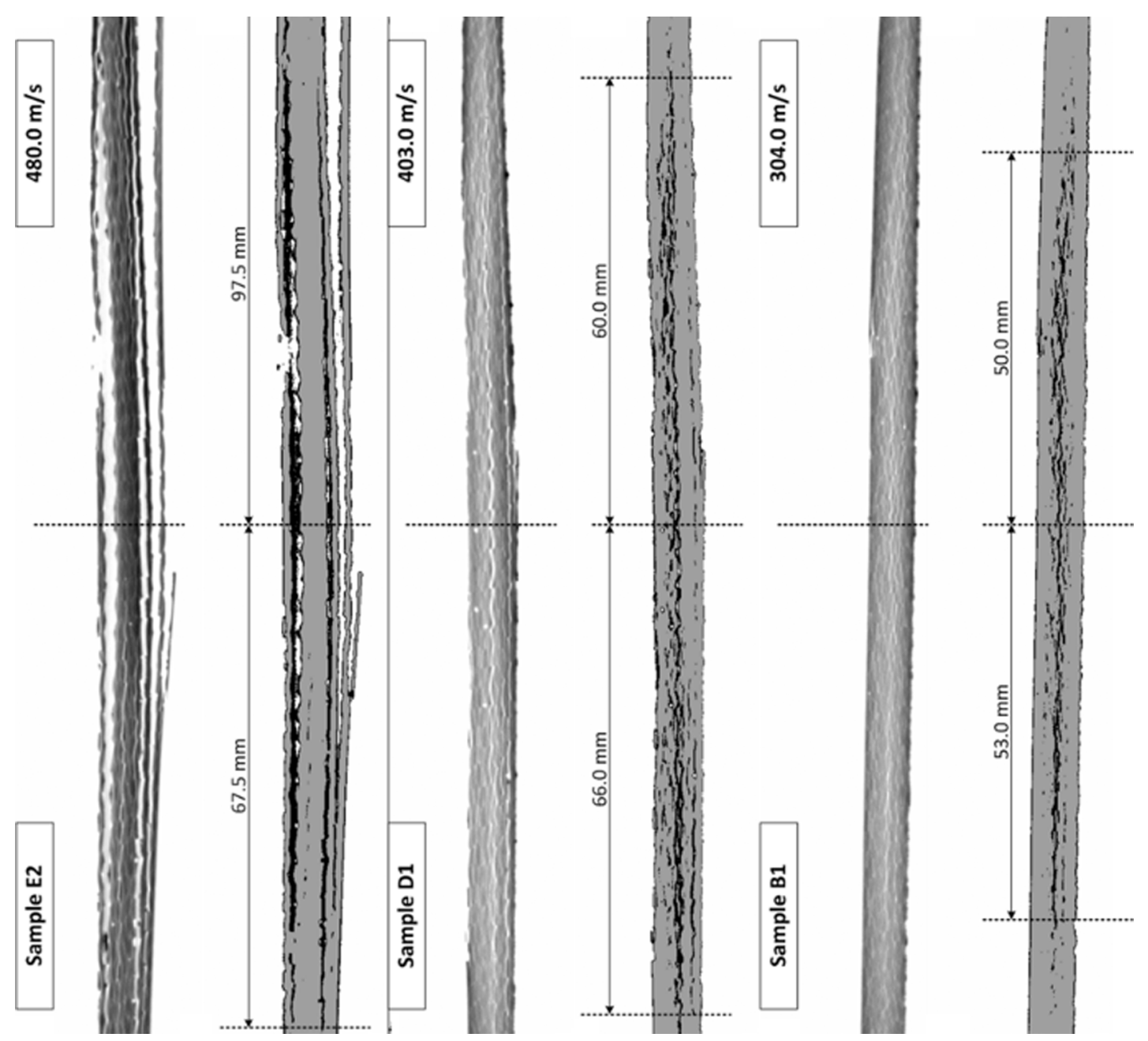

Fig. 19. Effect of velocity on damage caused by steel projectiles, $2 \mathrm{D}$ analysis along $\mathrm{CD}$ (see Fig. 3a).

the ice projectile on impact, leading to a distributed loading and, therefore, a longer impact duration.

Both kinds of projectiles and respective impact regimes resulted in two distinct types of visual damage, while the damage-cloud area and through-thickness damage increased with the growing impact energy for both projectiles. The solid projectiles in all cases caused localised indentation to the front surfaces that increased slightly as the impact energy grew. This subsequently led to the appearance of tensile failure of the plies at the rear surface as the projectile penetrated further into the specimens. In contrast, the fragmenting nature of the ice projectiles resulted in partial indentation into the specimen, but upon fragmentation within the front sub-surface plies (with its depth depending on the impact energy), the remains of the projectile caused catastrophic delamination of the first few front surface plies with no clear signs of any further penetration. For this projectile type, given the widespread nature of resulting visual damage, the damage cloud clearly increased in its area as the impact energy increased until almost the whole frontsurface plies were removed.

All the obtained qualitative observations and quantitative assessments of deformation and damage due to ballistic impacts with steel and ice projectiles were used to develop and validate a numerical approach, presented in Part II of the paper.

\section{Acknowledgement}

The study was partially supported by the Government of Perm Krai, Russia, research project No. C-26/790. 
Table 4

Maximum out-of-plane displacements and damage clouds for ballistic impacts with steel and ice projectiles.

\begin{tabular}{|c|c|c|c|c|c|c|c|c|}
\hline & Damage level & Sample & $\begin{array}{l}\text { Initial velocity } \\
(\mathrm{m} / \mathrm{s})\end{array}$ & $\begin{array}{l}\text { Incident } \\
\text { energy }(\mathrm{J})\end{array}$ & $\begin{array}{l}\text { Max out-of-plane } \\
\text { displacement }(\mathrm{mm})\end{array}$ & $\begin{array}{l}\text { Damage cloud } \\
\text { horizontal }(\mathrm{mm})\end{array}$ & $\begin{array}{l}\text { Damage cloud } \\
\text { vertical (mm) }\end{array}$ & $\begin{array}{l}\text { Damage cloud } \\
\text { area }\left(\mathrm{mm}^{2}\right)\end{array}$ \\
\hline \multirow[t]{12}{*}{ Steel } & \multirow[t]{4}{*}{ Major } & D4 & 91.4 & 228.5 & - & 55.0 & 71.0 & 3067.0 \\
\hline & & E3 & 91.2 & 227.5 & - & 62.0 & 66.5 & 3238.2 \\
\hline & & E5 & 91.8 & 230.5 & - & 66.0 & 71.0 & 3680.4 \\
\hline & & Average & 91.5 & 229.0 & - & - & - & 3250.6 \\
\hline & \multirow[t]{4}{*}{ Medium } & C3 & 78.4 & 168.1 & 8.00 & 50.0 & 53.5 & 2100.9 \\
\hline & & D2 & 78.6 & 169.0 & 8.88 & 62.5 & 63.0 & 3092.5 \\
\hline & & D5 & 78.4 & 168.1 & 7.59 & 46.4 & 52.0 & 1895.0 \\
\hline & & Average & 78.5 & 168.5 & 8.16 & - & - & 1696.0 \\
\hline & \multirow[t]{4}{*}{ Minor } & B2 & 59.4 & 96.5 & 7.23 & 38.0 & 41.5 & 1238.6 \\
\hline & & B4 & 60.0 & 98.5 & 7.36 & 35.0 & 43.0 & 1182.0 \\
\hline & & B5 & 59.0 & 95.2 & 7.27 & 33.0 & 74.5 & 1930.9 \\
\hline & & Average & 59.5 & 96.8 & 7.29 & - & - & 1450.5 \\
\hline \multirow[t]{12}{*}{ Ice } & \multirow[t]{4}{*}{ Major } & E1 & 481.0 & 867.6 & - & 195.0 & 165.0 & 32175.0 \\
\hline & & E2 & 480.0 & 864.0 & - & 195.0 & 165.0 & 32175.0 \\
\hline & & E4 & 479.0 & 860.4 & - & 195.0 & 163.0 & 31785.0 \\
\hline & & Average & 480.0 & 864.0 & - & - & - & 32045.0 \\
\hline & \multirow[t]{4}{*}{ Medium } & C2 & 402.0 & 606.0 & 6.63 & 135.0 & 107.0 & 11345.1 \\
\hline & & D1 & 403.0 & 609.0 & 6.60 & 148.0 & 126.0 & 14646.1 \\
\hline & & D3 & 402.0 & 606.0 & 6.42 & 139.0 & 124.5 & 13591.7 \\
\hline & & Average & 403.0 & 609.0 & 6.55 & - & - & 13194.3 \\
\hline & \multirow[t]{4}{*}{ Minor } & A4 & 304.0 & 346.6 & 5.35 & 56.0 & 76.0 & 3342.6 \\
\hline & & B1 & 304.0 & 346.6 & 5.95 & 60.0 & 103.0 & 4853.8 \\
\hline & & B3 & 303.0 & 344.3 & 5.88 & 41.0 & 71.0 & 2286.3 \\
\hline & & Average & 304.0 & 346.6 & 5.73 & - & - & 3494.2 \\
\hline
\end{tabular}

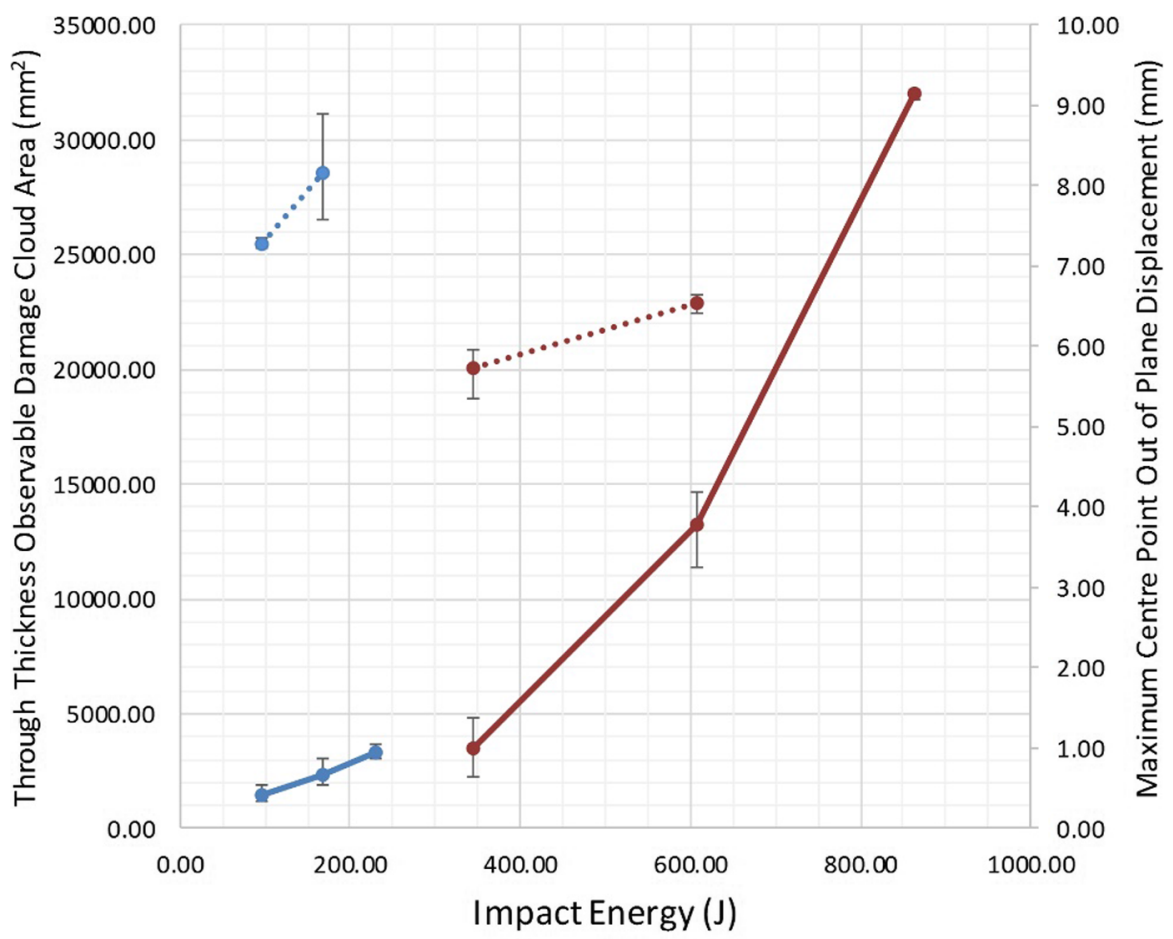

Damage Cloud Area - Rigid Steel
$\ldots$ O.. Dut of Plane Distplacement - Rigid Steel

Fig. 20. Comparison of damage cloud area for steel and ice projectiles. 


\section{References:}

[1] Abrate S. Impact on laminated composites: recent advances. Appl Mech Rev 1994;47:517-44. https://doi.org/10.1115/1.3111065.

[2] Abrate S. Impact on laminated composite materials. Appl Mech Rev 1991;44:155-90. https://doi.org/10.1115/1.3119500.

[3] Cantwell WJ, Morton J. Comparison of the low and high velocity impact response of CFRP. Composites 1989;20:545-51. https://doi.org/10.1016/00104361(89)90913-0.

[4] Hazell PJ, Kister G, Stennett C, Bourque P, Cooper G. Normal and oblique penetration of woven CFRP laminates by a high velocity steel sphere. Compos Part A Appl Sci Manuf 2008;39:866-74. https://doi.org/10.1016/j.compositesa.2008.01.007.

[5] Yashiro S, Ogi K, Nakamura T, Yoshimura A. Characterization of high-velocity impact damage in CFRP laminates: Part I - Experiment. Compos Part A Appl Sci Manuf 2013;48:93-100. https://doi.org/10.1016/j.compositesa.2012.12.015.

[6] Shaktivesh, Nair NS, Sesha Kumar CV, Naik NK. Ballistic impact performance of composite targets. Mater Des 2013;51:833-46. https://doi.org/10.1016/j. matdes.2013.04.093.

[7] Pandya KS, Pothnis JR, Ravikumar G, Naik NK. Ballistic impact behavior of hybrid composites. Mater Des 2013;44. https://doi.org/10.1016/j.matdes.2012.07. 044.

[8] Cantwell WJ, Morton J. The impact resistance of composite materials — a review. Composites 1991;22:347-62. https://doi.org/10.1016/0010-4361(91) 90549-V.

[9] Hazell PJ, Cowie A, Kister G, Stennett C, Cooper GA. Penetration of a woven CFRP laminate by a high velocity steel sphere impacting at velocities of up to 1875m/s. Int J Impact Eng 2009;36:1136-42. https://doi.org/10.1016/j.ijimpeng.2008.12.001.

[10] Karthikeyan K, Russell BP, Fleck NA, Wadley HNG, Deshpande VS. The effect of shear strength on the ballistic response of laminated composite plates. Eur J Mech - A/Solids 2013;42:35-53. https://doi.org/10.1016/j.euromechsol.2013.04.002.

[11] Silberschmidt VV, editor. Dynamic deformation, damage and fracture in composite materials and structures. Amsterdam, e.a.: Elsevier; 2016. p. 616.

[12] Appleby-Thomas GJ, Hazell PJ, Dahini G. On the response of two commercially-important CFRP structures to multiple ice impacts. Compos Struct 2011;93:2619-27. https://doi.org/10.1016/j.compstruct.2011.04.029.

[13] Batto RA, Schulson EM. On the ductile-to-brittle transition in ice under compression. Acta Metall Mater 1993;41:2219-25. https://doi.org/10.1016/09567151(93)90391-5.

[14] Schulson E. The brittle compressive fracture of ice. Acta Metall Mater 1990;38:1963-76. https://doi.org/10.1016/0956-7151(90)90308-4.

[15] Mellor M, Cole DM. Deformation and failure of ice under constant stress or constant strain-rate. Cold Reg Sci Technol 1982;5:201-19. https://doi.org/10.1016/ 0165-232X(82)90015-5.

[16] Schulson EM. The brittle failure of ice under compression. J Phys Chem B 1997. https://doi.org/10.1021/JP9632192.

[17] Jones SJ. High strain-rate compression tests on ice. J Phys Chem B 1997. https://doi.org/10.1021/JP963162J.

[18] Combescure A, Chuzel-Marmot Y, Fabis J. Experimental study of high-velocity impact and fracture of ice. Int J Solids Struct 2011;48:2779-90. https://doi.org/ 10.1016/J.IJSOLSTR.2011.05.028.

[19] Pernas-Sánchez J, Artero-Guerrero JA, Varas D, López-Puente J. Analysis of ice impact process at high velocity. Exp Mech 2015;55:1669-79. https://doi.org/10. 1007/s11340-015-0067-4.

[20] Sevkat E. Experimental and numerical approaches for estimating ballistic limit velocities of woven composite beams. Int J Impact Eng 2012;45:16-27. https:// doi.org/10.1016/j.ijimpeng.2012.01.007.

[21] Nunes LM, Paciornik S, d'Almeida JRM. Evaluation of the damaged area of glass-fiber-reinforced epoxy-matrix composite materials submitted to ballistic impacts. Compos Sci Technol 2004;64:945-54. https://doi.org/10.1016/S0266-3538(03)00105-2.

[22] Baucom JN, Zikry MA, Rajendran AM. Low-velocity impact damage accumulation in woven S2-glass composite systems. Compos Sci Technol 2006;66:1229-38. https://doi.org/10.1016/j.compscitech.2005.11.005.

[23] Naik N, Ramasimha R, Arya H, Prabhu S, ShamaRao N. Impact response and damage tolerance characteristics of glass-carbon/epoxy hybrid composite plates. Compos Part B Eng 2001;32:565-74. https://doi.org/10.1016/S1359-8368(01)00036-1.

[24] Hosur MV, Adbullah M, Jeelani S. Studies on the low-velocity impact response of woven hybrid composites. Compos Struct 2005;67:253-62. https://doi.org/10. 1016/j.compstruct.2004.07.024.

[25] Sevkat E, Liaw B, Delale F, Raju BB. Drop-weight impact of plain-woven hybrid glass-graphite/toughened epoxy composites. Compos Part A Appl Sci Manuf 2009;40:1090-110. https://doi.org/10.1016/j.compositesa.2009.04.028.

[26] Walter TR, Subhash G, Sankar BV, Yen CF. Damage modes in 3D glass fiber epoxy woven composites under high rate of impact loading. Compos Part B Eng 2009;40:584-9. https://doi.org/10.1016/j.compositesb.2009.04.021.

[27] Yahaya R, Sapuan SM, Jawaid M, Leman Z, Zainudin ES. Quasi-static penetration and ballistic properties of kenaf-aramid hybrid composites. Mater Des 2014;63:775-82. https://doi.org/10.1016/j.matdes.2014.07.010.

[28] Luan K, Sun B, Gu B. Ballistic impact damages of 3-D angle-interlock woven composites based on high strain rate constitutive equation of fiber tows. Int J Impact Eng 2013;57:145-58. https://doi.org/10.1016/j.ijimpeng.2013.02.003.

[29] Pernas-Sánchez J, Artero-Guerrero JA, Varas D, López-Puente J. Experimental analysis of ice sphere impacts on unidirectional carbon/epoxy laminates. Int J Impact Eng 2016;96:1-10. https://doi.org/10.1016/j.ijimpeng.2016.05.010.

[30] Schoeppner GA, Abrate S. Delamination threshold loads for low velocity impact on composite laminates. Compos Part A Appl Sci Manuf 2000;31:903-15. https://doi.org/10.1016/S1359-835X(00)00061-0.

[31] Muñoz R, Martínez-Hergueta F, Gálvez F, González C, LLorca J. Ballistic performance of hybrid 3D woven composites: experiments and simulations. Compos Struct 2015;127:141-51. https://doi.org/10.1016/j.compstruct.2015.03.021.

[32] Seltzer R, González C, Muñoz R, LLorca T, Blanco-Varela T. X-ray microtomography analysis of the damage micromechanisms in 3D woven composites under low-velocity impact. Compos Part A Appl Sci Manuf 2013;45:49-60. https://doi.org/10.1016/j.compositesa.2012.09.017.

[33] Sket F, Seltzer R, Molina-Aldareguía JM, Gonzalez C, LLorca J. Determination of damage micromechanisms and fracture resistance of glass fiber/epoxy cross-ply laminate by means of X-ray computed microtomography. Compos Sci Technol 2012;72:350-9. https://doi.org/10.1016/j.compscitech.2011.11.025.

[34] Schilling PJ, Karedla BR, Tatiparthi AK, Verges MA, Herrington PD. X-ray computed microtomography of internal damage in fiber reinforced polymer matrix composites. Compos Sci Technol 2005;65:2071-8. https://doi.org/10.1016/j.compscitech.2005.05.014.

[35] Toso N, Johnson A. LIBCOS-Load upon impact behaviour of composite structure. Res Project EASA.2009/3. 2011.

[36] Lecompte D, Bossuyt S, Cooreman S, Sol H, Vantomme J. Study and generation of optimal speckle patterns for DIC. Proc Annu Conf Expo Exp Appl Mech 2007;3:1643-9. 